\title{
A Comparative Kinetics Study between Cu/SSZ-13 and Fe/SSZ-13 SCR Catalysts
}

\author{
Feng Gao*, Yilin Wang, Márton Kollár, Nancy M. Washton, János Szanyi, Charles H.F. Peden* \\ Institute for Integrated Catalysis, Pacific Northwest National Laboratory, P.O. Box 999, Richland, WA \\ 99352, United States
}

\begin{abstract}
:
$\mathrm{Cu}-$ and $\mathrm{Fe} / \mathrm{SSZ}-13$ catalysts with the same $\mathrm{Cu}(\mathrm{Fe}) / \mathrm{Al}$ ratios are synthesized using the same parent SSZ-13 starting material. The catalytic performance for both fresh and hydrothermally aged catalysts is tested with $\mathrm{NO}$ and $\mathrm{NH}_{3}$ oxidation, and standard $\mathrm{SCR}$ reactions under steady-state conditions, and standard and fast SCR under temperature-programmed conditions. For standard SCR, Cu/SSZ-13 shows much better low-temperature performance which can be explained by $\mathrm{NH}_{3}$-inhibition of Fe/SSZ13. During hydrothermal aging, both catalysts undergo dealumination but Fe/SSZ-13 dealuminates more severely. For aged catalysts, $\mathrm{Cu} / \mathrm{SSZ}-13$ gains oxidation activities due to formation of $\mathrm{CuO}_{\mathrm{x}}$. However, Fe/SSZ-13 loses oxidation activities although formation of $\mathrm{FeO}_{\mathrm{x}}$ clusters and $\mathrm{FeAlO}_{\mathrm{x}}$ species also occur. Because of such physical properties differences, aged Cu/SSZ-13 loses while Fe/SSZ-13 maintains hightemperature SCR selectivities. A physical mixture of aged catalysts provides stable SCR performance in a wide temperature range and is able to decrease $\mathrm{N}_{2} \mathrm{O}$ formation at high reaction temperatures. This suggests that Fe/SSZ-13 can be used as a cocatalyst for Cu/SSZ-13 for transportation applications. During temperature-programmed SCR reactions, weak hysteresis is found during standard SCR due to $\mathrm{NH}_{3}$ inhibition. For fast SCR, hysteresis caused by $\mathrm{NH}_{4} \mathrm{NO}_{3}$ inhibition is much more significant. $\mathrm{NH}_{4} \mathrm{NO}_{3}$ deposition is greatly enhanced by Brønsted and Lewis acidity of the catalysts.
\end{abstract}

Key words: Selective catalytic reduction, chabazite, SSZ-13, diesel engine, emission control.

*Corresponding authors. Email addresses: feng.gao@pnnl.gov (F. Gao), and chuck.peden@pnnl.gov (C.H.F. Peden). 


\section{Introduction}

Zeolite-based selective catalytic reduction (SCR) catalysts, notably $\mathrm{Cu} / \mathrm{Chabazite}$ and $\mathrm{Fe} / \mathrm{Beta}$, have received intensive recent research interest since they meet the requirements for commercialization as part of diesel engine exhaust aftertreatment catalytic systems [1-6]. $\mathrm{Cu} / \mathrm{CHA}$ (including $\mathrm{Cu} / \mathrm{SSZ}-13$ and $\mathrm{Cu} / \mathrm{SAPO}-34$ ) has been especially well studied in the past few years [7-23]. Under certain circumstances, e.g., at relatively low $\mathrm{Cu} / \mathrm{Al}$ ratios and for dehydrated samples, the nature and positioning of $\mathrm{Cu}$ ions in $\mathrm{Cu} / \mathrm{SSZ}-13$ are now wellunderstood. It is generally agreed that $\mathrm{Cu}^{2+}$ ions prefer faces of 6-membered rings (6MRs) with coordination to two Al associated ion-exchange sites. Several studies have suggested that these are the SCR active centers under reaction conditions [7-9]. However, from our recent detailed SCR reaction kinetics study, catalytically active $\mathrm{Cu}^{2+}$ ions are not located in faces of $6 \mathrm{MRs}$ at relatively low temperature reaction conditions $\left(\leq 250{ }^{\circ} \mathrm{C}\right)$ due to strong solvation effects from $\mathrm{H}_{2} \mathrm{O}$ and/or $\mathrm{NH}_{3}$ [23], and might be in the form of $[\mathrm{Cu}(\mathrm{OH})]^{+}$[24] or even $\mathrm{Cu}$ dimers (e.g., $\left.\left[\mathrm{Cu}-\mu(\mathrm{OH})_{2}-\mathrm{Cu}\right]^{2+}\right)[23]$ instead of naked $\mathrm{Cu}^{2+}$. Only at high reaction temperatures $\left(\geq 350^{\circ} \mathrm{C}\right)$ do $\mathrm{Cu}^{2+}$ ions lose their $\mathrm{H}_{2} \mathrm{O}$ and/or $\mathrm{NH}_{3}$ solvation shell, and then migrate to faces of $6 \mathrm{MRs}$ and serve as active centers. Standard $\mathrm{NH}_{3}-\mathrm{SCR}$ is characterized with high apparent activation energies of $\sim 140 \mathrm{~kJ} / \mathrm{mol}$ in this high-temperature regime, much higher than low-temperature activation energies obtained for $\mathrm{Cu} / \mathrm{CHA}$ catalysts (typically $<\sim 80 \mathrm{~kJ} / \mathrm{mol}$ ) $[9,10,23]$.

In contrast, not much work has focused on Fe/CHA catalysts. Recently, we published the first detailed characterization and SCR performance study of freshly prepared and hydrothermally aged (HTA) Fe/SSZ-13 catalysts [25]. Using Mössbauer and FTIR spectroscopies, the likely monomeric and dimeric ferric ions in the hydrated fresh sample were determined to be $\left[\mathrm{Fe}(\mathrm{OH})_{2}\right]^{+}$and $[\mathrm{HO}-\mathrm{Fe}-\mathrm{O}-\mathrm{Fe}-\mathrm{OH}]^{2+}$, although their precise positioning is not yet known. Following a harsh HTA treatment at $800{ }^{\circ} \mathrm{C}$ for $16 \mathrm{~h}$ in the presence of $10 \% \mathrm{H}_{2} \mathrm{O}$, the 
majority of Fe-containing moieties convert to $\mathrm{FeAlO}_{\mathrm{x}}$ and $\mathrm{FeO}_{\mathrm{x}}$ cluster species, yet the Chabazite structure and a portion of extra framework cationic Fe species are still present. From the application point of view, Fe/SSZ-13 maintains high-temperature SCR activity and selectivity after hydrothermal aging, suggesting that it certainly holds the potential for practical application.

The different characteristics for $\mathrm{Cu}$ and Fe/zeolite SCR catalysts make direct comparison an interesting subject. In brief summary, previous literature has discovered the following differences between the two catalysts [26-30]: (1) Fe/zeolites typically have low standard SCR activities at temperatures below $250{ }^{\circ} \mathrm{C}$ due to strong $\mathrm{NH}_{3}$ inhibition effects at such low temperatures. In contrast, $\mathrm{Cu}$ /zeolites can be highly active even at $\sim 200{ }^{\circ} \mathrm{C}$. (2) $\mathrm{Cu} / \mathrm{zeolites}$ are much less sensitive to $\mathrm{NO}_{2} / \mathrm{NO}_{\mathrm{x}}$ ratios in the reactant feed. $\mathrm{NO}_{\mathrm{x}}$ conversion differences between standard $\left(\mathrm{NO}_{2} / \mathrm{NO}_{\mathrm{x}}=0\right)$ and fast $\left(\mathrm{NO}_{2} / \mathrm{NO}_{\mathrm{x}}=0.5\right) \mathrm{SCR}$ are often rather marginal for $\mathrm{Cu} /$ zeolite catalysts. In contrast for Fe/zeolites, $\mathrm{NO}_{2} / \mathrm{NO}_{\mathrm{x}}=0.5$ is clearly the preferred ratio for lowtemperature reactivity. (3) Fe/zeolites are typically less selective in $\mathrm{N}_{2} \mathrm{O}$ formation, especially at $\mathrm{NO}_{2} / \mathrm{NO}_{\mathrm{x}} \leq 0.5$

In the following, we for the first time present a detailed comparison between fresh and aged $\mathrm{Cu}$ - and Fe/SSZ-13 catalysts with respect to SCR kinetics obtained at both steady-state and with temperature-programmed reaction conditions. To make a fair comparison, catalysts were prepared with the same $\mathrm{Cu}(\mathrm{Fe}) / \mathrm{Al}$ ratio of 0.2 , using the same $\mathrm{SSZ}-13$ substrate $(\mathrm{Si} / \mathrm{Al}=12)$. Some of the results for Fe/SSZ-13 have been published recently [25] but are included here for the purpose of comparison.

\section{Experimental}

\subsection{Catalyst synthesis}


A Na/SSZ-13 sample with $\mathrm{Si} / \mathrm{Al}=12$ was hydrothermally synthesized using a method modified slightly from a protocol developed recently by Deka, et al. [9]. Composition of the gel was the following: 10SDA: $10 \mathrm{NaOH}: 4 \mathrm{Al}_{2} \mathrm{O}_{3}: 100 \mathrm{SiO}_{2}: 2200 \mathrm{H}_{2} \mathrm{O}$. The gel was prepared by first dissolving $\mathrm{NaOH}$ (99.95\%, Aldrich) in deionized water and adding the SDA (TMAda-OH, Sachem ZeoGen 2825). Following this, $\mathrm{Al}(\mathrm{OH})_{3}$ (containing $~ 54 \% \mathrm{Al}_{2} \mathrm{O}_{3}$, Aldrich) and fumed silica $(0.007 \mu \mathrm{m}$ average particle size, Aldrich) were added sequentially under vigorous stirring until the gel was homogenized. The gel (with a stir bar in) was then sealed into a $125 \mathrm{ml}$ Teflonlined stainless steel autoclave. Subsequently, the autoclave was placed in a salt bath on top of a hot plate stirrer to carry out hydrothermal synthesis at $160{ }^{\circ} \mathrm{C}$ for $96 \mathrm{~h}$ under continuous stirring (300 rpm). After synthesis, Na/SSZ-13 was separated from the mother liquid via centrifugation and washed with deionized water for 3 times. Finally, the zeolite powders were dried at $120{ }^{\circ} \mathrm{C}$ under flowing $\mathrm{N}_{2}$, and calcined in static air to remove the SDA. In this latter process, a thin layer of powder sample well-dispersed in a ceramic plate was heated to $550{ }^{\circ} \mathrm{C}$ at $2{ }^{\circ} \mathrm{C} / \mathrm{min}$ and maintained at $550{ }^{\circ} \mathrm{C}$ for $8 \mathrm{~h}$. Si and $\mathrm{Al}$ contents of the product powders were measured with Inductively Coupled Plasma Atomic Emission Spectroscopy (ICP-AES) at Galbraith Laboratories (Knoxville, TN, USA). Prior to measurements, the sample was dehydrated at 150 ${ }^{\circ} \mathrm{C}$ for $2 \mathrm{~h}$ in vacuum to remove adsorbed moisture.

$\mathrm{Cu} / \mathrm{SSZ}-13$ was prepared using a two-step solution ion exchange protocol [16]. First, $\mathrm{Na} / \mathrm{SSZ}-13$ was exchanged to $\mathrm{NH}_{4} / \mathrm{SSZ}-13$ using a $0.1 \mathrm{M} \mathrm{NH}_{4} \mathrm{NO}_{3}$ solution at $80{ }^{\circ} \mathrm{C}$. After separation, washing with deionized water and drying in flowing $\mathrm{N}_{2}$ at $120{ }^{\circ} \mathrm{C}$ to obtain the $\mathrm{NH}_{4} / \mathrm{SSZ}-13$ powder, a second ion exchange was performed using a $0.01 \mathrm{M} \mathrm{CuSO}_{4}$ solution at $80{ }^{\circ} \mathrm{C}$ for $1 \mathrm{~h}$ at a $\mathrm{pH}$ of $\sim 3.0$. After that, $\mathrm{Cu} / \mathrm{SSZ}-13$ was collected, washed and dried. Fe/SSZ-13 was prepared similarly using $\mathrm{NH}_{4} / \mathrm{SSZ}_{-13}$ and $\mathrm{FeSO}_{4}$; however, care must be taken to avoid $\mathrm{Fe}^{2+}$ oxidation to $\mathrm{Fe}^{3+}$ which leads to bulky Fe-complexes during ion exchange. This was achieved by 
$\mathrm{N}_{2}$ protection during ion exchange and more details can be found elsewhere [25]. The asprepared powders were first calcined in static air at $550{ }^{\circ} \mathrm{C}$ for $8 \mathrm{~h}$. Samples thus obtained are denoted as "fresh" here. A portion of fresh samples were hydrothermally aged at $800{ }^{\circ} \mathrm{C}$ for $16 \mathrm{~h}$ in flowing air containing $10 \% \mathrm{H}_{2} \mathrm{O}$ (denoted as "HTA" samples). In order for a fair comparison to be made, $\mathrm{Cu} / \mathrm{Al}$ and $\mathrm{Fe} / \mathrm{Al}$ ratios were both chosen as 0.2 for the $\mathrm{Cu} / \mathrm{SSZ}-13$ and $\mathrm{Fe} / \mathrm{SSZ}-13$ catalysts. $\mathrm{Cu}$ and $\mathrm{Fe}$ contents of the catalysts were also determined via ICP-AES.

\subsection{NO/NH $\mathrm{NH}_{3}$ oxidation and standard/fast $\mathrm{NH}_{3}-\mathrm{SCR}$ reaction tests}

$\mathrm{NO} / \mathrm{NH}_{3}$ oxidation and $\mathrm{NH}_{3}-\mathrm{SCR}$ reaction kinetics were measured using a plug-flow reaction system described elsewhere [16]. Powder samples were pressed, crushed and sieved $(0.177-0.25 \mathrm{~mm})$ prior to use. For "standard" SCR $\left(4 \mathrm{NO}+4 \mathrm{NH}_{3}+\mathrm{O}_{2}=4 \mathrm{~N}_{2}+6 \mathrm{H}_{2} \mathrm{O}\right)$, the feed gas contained $350 \mathrm{ppm} \mathrm{NO}, 350 \mathrm{ppm} \mathrm{NH}_{3}, 14 \% \mathrm{O}_{2}, \sim 2.5 \% \mathrm{H}_{2} \mathrm{O}$, and balance $\mathrm{N}_{2}$. For "fast" SCR $\left(\mathrm{NO}+\mathrm{NO}_{2}+2 \mathrm{NH}_{3}=2 \mathrm{~N}_{2}+3 \mathrm{H}_{2} \mathrm{O}\right)$, the feed gas contained $175 \mathrm{ppm} \mathrm{NO}$ and $175 \mathrm{ppm} \mathrm{NO}$, and other components were the same as standard SCR. $\mathrm{NO}\left(\mathrm{NH}_{3}\right)$ oxidation reaction was conducted in the same manner, without adding $\mathrm{NH}_{3}(\mathrm{NO})$ to the feed. Some kinetic measurements were carried out at steady-state. In this case, measurements were conducted from high to low reaction temperatures, and samples were maintained at each target temperature for $\sim 50 \mathrm{~min}$ to reach a steady-state before moving to the next (lower) temperature. Some temperature-programmed reaction measurements were also performed by linearly heating the samples from 100 to $500{ }^{\circ} \mathrm{C}$ and cooling back to $100{ }^{\circ} \mathrm{C}$ at $2{ }^{\circ} \mathrm{C} / \mathrm{min}$. All of the gas lines were heated to over $100{ }^{\circ} \mathrm{C}$ to avoid water condensation. The total gas flow was $300 \mathrm{sccm}$, and the gas hourly space velocity (GHSV)

was estimated to be $\sim 200,000 \mathrm{~h}^{-1}$ for a catalyst amount of $60 \mathrm{mg}$. Concentrations of reactants and products were measured by an online Nicolet Magna 560 FTIR spectrometer with a 2 m gas cell maintained at $150{ }^{\circ} \mathrm{C}$. In this study, catalytic performance is mainly reported as conversion 
versus temperature (i.e., light-off) curves. Equations used to calculate reactant conversions can be found elsewhere [16].

\section{Results}

\subsection{Steady-state reaction results}

Fig. 1 compares light-off curves in standard SCR for fresh $\mathrm{Cu}-$ and Fe/SSZ-13 catalysts. Both $\mathrm{NO}$ and $\mathrm{NH}_{3}$ conversions are plotted so that SCR selectivities can also be readily compared. For the $\mathrm{Cu} / \mathrm{SSZ}-13$ catalyst, the light-off temperature is slightly below $200{ }^{\circ} \mathrm{C}$ and over the entire temperature ranges investigated here, SCR selectivities are excellent (i.e., NO and $\mathrm{NH}_{3}$ conversions are essentially equal at all temperatures). In contrast, Fe/SSZ-13 displays no activity below $200{ }^{\circ} \mathrm{C}$ and only becomes highly active above $\sim 300{ }^{\circ} \mathrm{C}$. To emphasize the difference, the temperature at $50 \%$ NO conversion $\left(\mathrm{T}_{50}\right)$ for $\mathrm{Cu} / \mathrm{SSZ}-13$ is $\sim 120{ }^{\circ} \mathrm{C}$ lower than that for Fe/SSZ-13. It is generally believed that the poor SCR activity for Fe/zeolites at low temperatures is due to $\mathrm{NH}_{3}$ inhibition $[31,32]$. This point will be discussed in more detail below. It is also clear from Fig. 1 that, at $275^{\circ} \mathrm{C}$ and above, SCR selectivities on Fe/SSZ-13 is $\sim 90 \%$ in terms of $\mathrm{NH}_{3}$ conversion; that is, $\sim 10 \% \mathrm{NH}_{3}$ overconsumption via non-selective oxidation reaction is evident.

Figs. 2(a) and (b) present light-off curves for the HTA Fe/SSZ-13 and Cu/SSZ-13 catalysts, respectively. For both catalysts, performance becomes somewhat inferior as compared to their fresh counterparts. Again, low-temperature activity for $\mathrm{Cu} / \mathrm{SSZ}-13$ is much better than Fe/SSZ-13. However at $\sim 400{ }^{\circ} \mathrm{C}$, NO conversions on both catalysts become comparable. Importantly, at $\sim 500{ }^{\circ} \mathrm{C}$ and above, catalytic performance for Fe/SSZ-13 is now clearly superior to $\mathrm{Cu} / \mathrm{SSZ}-13$. In this case, $\mathrm{Cu} / \mathrm{SSZ}-13$ substantially loses SCR selectivities due to non-selective $\mathrm{NH}_{3}$ oxidation, yet Fe/SSZ-13 maintains good SCR selectivities. 
$\mathrm{NO}$ and $\mathrm{NH}_{3}$ oxidation are relevant reactions to better understand SCR kinetics. Fig. 3(a) presents $\mathrm{NO}$ oxidation $\left(\mathrm{NO}+1 / 2 \mathrm{O}_{2}=\mathrm{NO}_{2}\right)$ results on fresh catalysts. Fresh Fe/SSZ-13 shows good activity; above $400{ }^{\circ} \mathrm{C}$, NO conversions are partially influenced by gas phase $\mathrm{NO} / \mathrm{NO}_{2}$ equilibrium. We have shown previously that, in the absence of moisture, this catalyst is even more active for this reaction [25]. In contrast, the fresh $\mathrm{Cu} / \mathrm{SSZ}-13$ used here is completely inert below $\sim 350{ }^{\circ} \mathrm{C}$ (the $\sim 2.5 \% \mathrm{NO}$ conversions come from background gas phase reactions), and only become marginally active at temperatures above $400{ }^{\circ} \mathrm{C}$. Interestingly, as displayed in Fig. 3(b), reactivity for Fe/SSZ-13 decreases considerably after aging, while Cu/SSZ-13 becomes much more active after aging. Above $400{ }^{\circ} \mathrm{C}$, NO conversions on HTA Cu/SSZ-13 surpass those on HTA Fe/SSZ-13, and the difference in rates increases with increasing temperature.

$\mathrm{NH}_{3}$ oxidation $\left(4 \mathrm{NH}_{3}+3 \mathrm{O}_{2}=2 \mathrm{~N}_{2}+6 \mathrm{H}_{2} \mathrm{O}\right)$ kinetics show some particularly interesting differences. As illustrated in Fig. 4(a), fresh Fe/SSZ-13 has no activity below $\sim 300{ }^{\circ} \mathrm{C}$, yet at 350 ${ }^{\circ} \mathrm{C}$ and above, $\mathrm{NH}_{3}$ conversions increase rather rapidly with temperature. Presumably, as with the case for standard SCR, low temperature activity is suppressed on this catalyst due to poisoning by adsorbed $\mathrm{NH}_{3}$. Fresh $\mathrm{Cu} / \mathrm{SSZ}-13$ displays rather complicated kinetic behavior with temperature. Notably, this catalyst has some low-temperature $\left(\leq 300^{\circ} \mathrm{C}\right)$ activity suggesting a lack of $\mathrm{NH}_{3}$ inhibition as opposed to Fe/SSZ-13. Between 300 and $400{ }^{\circ} \mathrm{C}$, the rather unusual behavior of relatively constant $\mathrm{NH}_{3}$ oxidation rates is observed. Above $400{ }^{\circ} \mathrm{C}, \mathrm{NH}_{3}$ conversion increases with increasing temperature again; however, this catalyst is clearly less active than Fe/SSZ-13 at such high temperatures. As shown in Fig. 4(b), HTA Fe/SSZ-13 is much less active for $\mathrm{NH}_{3}$ oxidation, where reactivity only becomes apparent at $\sim 450{ }^{\circ} \mathrm{C}$ and above. On the other hand, HTA Cu/SSZ-13 loses low-temperature $\left(\leq 300^{\circ} \mathrm{C}\right)$ activity, but gains considerable hightemperature activity as compared to the fresh sample. 
The different optimum operation temperature windows for $\mathrm{Cu}$ and Fe/zeolite catalysts evident in Figs. 1 and 2 make it a straightforward consideration to combine the two into a complex catalyst; and, in fact, this has already been practiced previously [26, 29, 30]. Using the $\mathrm{Cu}$ - and Fe/SSZ-13 catalysts studied here, we carried out a standard SCR reaction on a catalyst system made by mixing the HTA materials at a 1/1 ratio. As shown in Fig. 5(a), compared to the $\mathrm{Cu} / \mathrm{SSZ}-13$ catalyst alone, the low-temperature activity for this physical mixture is only slightly sacrificed yet the high-temperature selectivity appears to be improved. Importantly, the mixed catalyst gives very stable NO conversions over a wide temperature window from 200 to more than $500{ }^{\circ} \mathrm{C}$. Moreover, as shown in Fig. 5(b), HTA Fe/SSZ-13 is particularly unselective for the formation of the undesired byproduct, $\mathrm{N}_{2} \mathrm{O}$, yet HTA Cu/SSZ-13 performs poorly above $400{ }^{\circ} \mathrm{C}$ in this regard. The mixed catalyst is able to significantly lower $\mathrm{N}_{2} \mathrm{O}$ formation as compared to $\mathrm{Cu} / \mathrm{SSZ}-13$. Note especially that, at a reaction temperature of $550{ }^{\circ} \mathrm{C}, \mathrm{N}_{2} \mathrm{O}$ formation $(\sim 8 \mathrm{ppm})$ from the mixed catalyst is less than half of that by $\mathrm{Cu} / \mathrm{SSZ}-13(\sim 25 \mathrm{ppm})$. Even accounting for the fact that the amount of $\mathrm{Cu} / \mathrm{SSZ}-13$ in the mixed catalyst is $1 / 2$ the total used for kinetics measurements on $\mathrm{Cu} / \mathrm{SSZ}-13$ alone, the mixed catalyst is performing considerably better with respect to $\mathrm{N}_{2} \mathrm{O}$ formation (i.e., $12.5 \mathrm{ppm}$ versus $8 \mathrm{ppm}$ for the mixture). This suggests that there is indeed synergy between the two components perhaps by the decomposition of some $\mathrm{N}_{2} \mathrm{O}$ generated by $\mathrm{Cu} / \mathrm{SSZ}-13$ over the Fe/SSZ-13 component.

\subsection{Temperature-programmed reaction results}

Both standard and fast SCR reactions were also performed in a temperature-programmed reaction mode to study transient behaviors of the catalysts, and to specifically probe effects from $\mathrm{NH}_{3}$ storage and ammonium nitrate/nitrite deposition. The experimental procedure is as follows: a catalyst is first treated in an $\mathrm{O}_{2} / \mathrm{N}_{2}$ flow (300 sccm, containing $\sim 20 \% \mathrm{O}_{2}$ ) at $550{ }^{\circ} \mathrm{C}$ for $30 \mathrm{~min}$ to remove trapped carbonates and organics, and then cooled to $100{ }^{\circ} \mathrm{C}$ in the same flow. Reaction 
feeds are subsequently switched on $(\equiv$ time $=0)$ and the recording of gas outlet concentrations of various reactant and product species an on-line FTIR detector is initiated. The sample is maintained at $100{ }^{\circ} \mathrm{C}$ for $60 \mathrm{~min}$, and then ramped up to $500{ }^{\circ} \mathrm{C}$ at $2{ }^{\circ} \mathrm{C} / \mathrm{min}$, and then immediately ramped back down to $100{ }^{\circ} \mathrm{C}$ at the same rate. Finally, the sample is maintained at $100{ }^{\circ} \mathrm{C}$ until gas outlet values become approximately equal to inlet ones. Following this, the reaction feeds are turned off, and the sample is purged with pure $\mathrm{N}_{2}(300 \mathrm{sccm})$ for $60 \mathrm{~min}$ before a final temperature-programmed desorption (TPD) step. TPD is conducted by ramping the sample from 100 to $600{ }^{\circ} \mathrm{C}$ at $10{ }^{\circ} \mathrm{C} / \mathrm{min}$, and maintaining at $600{ }^{\circ} \mathrm{C}$ until desorption is complete.

Fig. 6(a) presents the temperature curve (dashed line) and $\mathrm{NO} / \mathrm{NO}_{2} / \mathrm{N}_{2} \mathrm{O} / \mathrm{NH}_{3}$ outlet curves (solid lines) as a function of time for standard SCR carried out on a fresh Fe/SSZ-13. The horizontal dot-dashed line represents $\mathrm{NO}$ and $\mathrm{NH}_{3}$ inlet concentrations (350 ppm each). Due to differences in the storage of these species on the catalyst, NO outlet values reach 350 ppm within $1 \mathrm{~min}$ at $100{ }^{\circ} \mathrm{C}$, while it takes $\sim 15 \mathrm{~min}$ for $\mathrm{NH}_{3}$ to reach its inlet value of $350 \mathrm{ppm}$. During the ramping steps, $\mathrm{NO}$ predominately undergoes $\mathrm{SCR}$ reaction while $\mathrm{NH}_{3}$ undergoes $\mathrm{SCR}$ reaction, non-selective oxidation reaction and storage. When $\mathrm{NH}_{3}$ outlet concentrations surpass $\mathrm{NO}$ ones (e.g., during the ramping up step from 350 to $\sim 400^{\circ} \mathrm{C}$ ), the "extra" $\mathrm{NH}_{3}$ comes from desorption of $\mathrm{NH}_{3}$ that was stored at lower temperatures. When $\mathrm{NO}$ outlet values surpass $\mathrm{NH}_{3}$ (e.g., during the ramping down step from 500 to $100{ }^{\circ} \mathrm{C}$ ), the extra $\mathrm{NH}_{3}$ consumption comes from nonselective oxidation and storage. For the case where $\mathrm{NO}$ and $\mathrm{NH}_{3}$ outlet values are equal (e.g., during the ramping up step from 100 to $\sim 350{ }^{\circ} \mathrm{C}$ ), $\mathrm{NH}_{3}$ is predominately consumed by SCR and $\mathrm{NH}_{3}$ adsorption/desorption or non-selective oxidation processes are negligible. Note also from Fig. 6(a) that $\mathrm{NO}_{2}$ and $\mathrm{N}_{2} \mathrm{O}$ are barely detectable during the whole process.

Fig. 6(b) presents data collected during fast SCR on a fresh Fe/SSZ-13 catalyst. Note that two dot-dashed horizontal lines are included representing $\mathrm{NO}$ and $\mathrm{NO}_{2}$ inlet values (175 ppm 
each), and $\mathrm{NH}_{3}$ inlet ones (350 ppm). During the first $60 \mathrm{~min}$ at $100{ }^{\circ} \mathrm{C}$, fast $\mathrm{SCR}$ does not proceed at appreciable rates as indicated by the nearly constant concentrations of NO that are only slightly lower than the inlet $175 \mathrm{ppm}$ values. However, extensive $\mathrm{NH}_{4} \mathrm{NO}_{3}$ storage must have occurred as indicated from the low $\mathrm{NO}_{2}$ and $\mathrm{NH}_{3}$ outlet concentrations. Note that $\mathrm{NO}$ is not involved in $\mathrm{NH}_{4} \mathrm{NO}_{3}$ formation at $100{ }^{\circ} \mathrm{C}$, as indicated by the fact that, again, its inlet and outlet concentrations are similar. The NO "spike" above the inlet of $175 \mathrm{ppm}$ during the first a few minutes is due to $\mathrm{NO}$ formation from the $\mathrm{NO}_{2}$ disproportionation reaction in the presence of $\mathrm{H}_{2} \mathrm{O}$ (i.e., $3 \mathrm{NO}_{2}+\mathrm{H}_{2} \mathrm{O}=2 \mathrm{HNO}_{3}+\mathrm{NO}$ ). During the ramping up step, small amounts of $\mathrm{N}_{2} \mathrm{O}$ are generated via $\mathrm{NH}_{4} \mathrm{NO}_{3}$ decomposition between 220 to $300{ }^{\circ} \mathrm{C}$, a process not observed during the cooling step. Note that $\mathrm{NO}_{2}$ concentrations have not returned to inlet values by 500 min (the program used to collect gas outlets only records data for this length of time). However even in this case, the sample was continuously held at $100{ }^{\circ} \mathrm{C}$ until $\mathrm{NO}_{2}$ and $\mathrm{NH}_{3}$ outlets become the same as inlets (i.e., until $\mathrm{NH}_{4} \mathrm{NO}_{3}$ storage saturates, not shown) prior to the subsequent TPD to be discussed below.

The same measurements were also conducted on HTA Fe/SSZ-13, and fresh and HTA $\mathrm{Cu} / \mathrm{SSZ}-13$. For the sake of brevity, the results are shown only in the Supplementary Information (Figs. S1-S3). As mentioned above, NO does not store during the temperature-programmed reaction steps; therefore, NO conversions can be calculated and compared at any reaction temperature based on data shown in Figs. 6 and S1-S3. Fig. S4 presents NO conversion versus temperature during steady-state and the cooling down step for the temperature-programmed standard SCR reactions on a fresh Fe/SSZ-13 catalyst. The similarity of these curves clearly demonstrates that a ramping rate of $2^{\circ} \mathrm{C} / \mathrm{min}$ is sufficiently slow such that $\mathrm{NO}$ can be deemed to be in a quasi-steady-state during the temperature-programmed reaction. Note that this is not the case for $\mathrm{NH}_{3}$ and $\mathrm{NO}_{2}$ where conversions cannot be readily calculated during temperature- 
programmed reactions. $\mathrm{N}_{2} \mathrm{O}$, another weakly-bound molecule, is expected to desorb immediately upon formation.

Next, details on $\mathrm{NO}$ conversions, $\mathrm{N}_{2} \mathrm{O}$ formation and TPD results after temperatureprogrammed reactions are presented. Results for fresh and HTA Fe/SSZ-13 are given in Figs. 7 and 8, with the corresponding data for Cu/SSZ-13 presented in Figs. 9 and 10.

Fig. 7(a) displays a direct comparison on NO conversions during the heating and cooling steps in standard SCR over fresh (upper panel) and HTA (lower panel) Fe/SSZ-13 catalysts. For the fresh catalyst, two interesting minor hysteresis loops are found; between 'A' and 'B', NO conversions during the cooling step are slightly higher whereas between ' $\mathrm{B}$ ' and ' $\mathrm{C}$ ', the reverse is evident. For the HTA sample, a single hysteresis loop is found between ' $\mathrm{D}$ ' and ' $\mathrm{E}$ ' where NO conversions are slightly higher during the cooling step. Fig. 7(b) plots results for fast SCR on the same two catalysts. In this case, hysteresis appears to be much more pronounced (especially for the HTA sample) as compared to standard SCR. It is also interesting to note that, (1) for the fresh catalyst, NO conversions appear to be unusually high during the onset of the heating step, likely due to $\mathrm{NO}$ reaction with the deposited $\mathrm{NH}_{4} \mathrm{NO}_{3}$. (2) light-off temperatures on the HTA sample in both heating and cooling steps are substantially lower than those for the fresh sample. This is somewhat surprising and will be discussed in more detail along with the TPD results. Fig. 7(c) presents $\mathrm{N}_{2} \mathrm{O}$ yield profiles during temperature-programmed fast SCR for the fresh and HTA Fe/SSZ-13 catalysts $\left(\mathrm{N}_{2} \mathrm{O}\right.$ formation during standard SCR on both samples are barely detectable so those data are not shown). For the fresh sample, significant $\mathrm{N}_{2} \mathrm{O}$ formation occurs between $\sim 220$ to $300{ }^{\circ} \mathrm{C}$ in the heating step likely due to the decomposition of deposited $\mathrm{NH}_{4} \mathrm{NO}_{3}$. At other temperatures for the fresh sample, as well as in the whole temperature range for the HTA sample, $\mathrm{N}_{2} \mathrm{O}$ formation yields in the heating and cooling steps are rather similar and fairly small. 
Fig. 8(a) presents TPD results following the temperature-programmed standard SCR reactions. For the fresh Fe/SSZ-13 (upper panel), no $\mathrm{NO}_{\mathrm{x}}$ desorption is detected. $\mathrm{NH}_{3}$ desorbs between $\sim 300$ to $600{ }^{\circ} \mathrm{C}$, predominately from Brønsted acid sites. $\mathrm{H}_{2} \mathrm{O}$ displays two desorption states: (1) low-temperature desorption below $\sim 200{ }^{\circ} \mathrm{C}$ is due to trapped $\mathrm{H}_{2} \mathrm{O}$, for example, via hydrogen-bonding interactions; and (2) the desorption feature between $\sim 300$ to $500{ }^{\circ} \mathrm{C}$ likely due to dehydration of Fe centers [25]. For the HTA sample, $\mathrm{NH}_{3}$ desorption becomes substantially weaker demonstrating a marked decrease in residual Brønsted acid sites for this sample. The high-temperature $\mathrm{H}_{2} \mathrm{O}$ desorption state is also absent suggesting a change in the nature of the $\mathrm{Fe}$ species during aging. Again, no $\mathrm{NO}_{\mathrm{x}}$ species desorb from the HTA sample. Fig. 8(b) depicts TPD results after fast SCR. For the fresh sample (upper panel), extremely weak NO desorption is found at $\sim 220{ }^{\circ} \mathrm{C}$, while a single prominent $\mathrm{NO}_{2}$ desorption state is observed at $\sim 240{ }^{\circ} \mathrm{C} . \mathrm{N}_{2} \mathrm{O}$ displays two desorption states at $\sim 220$ and $\sim 280{ }^{\circ} \mathrm{C}$, and $\mathrm{NH}_{3}$ appears to have weak desorption states at $\sim 220,240$ and $280{ }^{\circ} \mathrm{C}$, and a much stronger state from Brønsted acid sites at higher $\left(>350{ }^{\circ} \mathrm{C}\right.$ ) temperatures. $\mathrm{H}_{2} \mathrm{O}$ displays very strong desorption states at $\sim 220$ and $280{ }^{\circ} \mathrm{C}$, similar to $\mathrm{N}_{2} \mathrm{O}$. The higher-temperature $\mathrm{H}_{2} \mathrm{O}$ desorption state, due to $\mathrm{Fe}$ species dehydration, is still detected, yet the low-temperature state due to trapped $\mathrm{H}_{2} \mathrm{O}$ is now largely absent. With an online FTIR analyzer, $\mathrm{N}_{2}$ formation during TPD is unfortunately not detectable; however, $\mathrm{H}_{2} \mathrm{O}$ desorption between $\sim 200$ to $300{ }^{\circ} \mathrm{C}$ should be due entirely to decomposition of deposited $\mathrm{NH}_{4} \mathrm{NO}_{3}$, and to reactions between adsorbed $\mathrm{NH}_{3}$ and $\mathrm{NH}_{4} \mathrm{NO}_{3}$. Therefore, $\mathrm{H}_{2} \mathrm{O}$ yield in this temperature window provides a good measure of $\mathrm{NH}_{4} \mathrm{NO}_{3}$ deposition prior to TPD. In this sense, it is very interesting that $\mathrm{NH}_{4} \mathrm{NO}_{3}$ deposition is much less on the HTA sample (lower panel). For the latter, the $\sim 220{ }^{\circ} \mathrm{C} \mathrm{N}_{2} \mathrm{O}$ and $\mathrm{H}_{2} \mathrm{O}$ desorption states appear to be stronger than the $\sim 280{ }^{\circ} \mathrm{C}$ state, which is the opposite for the fresh sample. 
The temperature-programmed reaction results (Figs. S2 and S3) on fresh and HTA $\mathrm{Cu} / \mathrm{SSZ}-13$ are analyzed in the same way and these results are discussed next. Fig. 9(a) presents NO conversions on fresh and HTA samples in standard SCR. Note that the HTA sample used in these experiments was aged from a different batch as opposed to the sample used for steady-state measurements and appears to be slightly more active. Yet this does not change the key findings and main conclusions. For the fresh sample (upper panel), light-off occurs below $\sim 200{ }^{\circ} \mathrm{C}$, and low-temperature hysteresis appears to be very minor where NO conversions are slightly higher during the cooling step. During the cooling step, there is a drop in NO conversions between 300 and $400{ }^{\circ} \mathrm{C}$. This is caused by migration of $\mathrm{Cu}$ ion centers; phenomena that have been discussed in detail recently [23]. Note that a similar drop is not seen in this temperature range during the heating step because of complete NO conversions. For the fresh Fe/SSZ-13 (Fig. 7(a), between ' $\mathrm{B}$ ' and ' $\mathrm{C}$ '), NO conversions are also higher during the heating step in this temperature range. As will be shown below, the "extra" NO conversion during the heating step is due to reactivity of $\mathrm{NH}_{3}$ stored (at lower temperatures) on Brønsted acid sites. The HTA sample (Fig. 9(a), lower panel) shows comparable activities except that NO conversions decrease with increasing temperature due to non-selective $\mathrm{NH}_{3}$ oxidation above $\sim 400{ }^{\circ} \mathrm{C}$. Fig. 9(b) displays $\mathrm{NO}$ conversions during fast SCR. In the low-temperature $\left(<250{ }^{\circ} \mathrm{C}\right)$ regime, both the fresh and HTA samples show strong hysteresis, where NO conversions during the cooling step are substantially higher than during the heating step. In the high temperature regime, excellent SCR selectivity maintains up to $\sim 450{ }^{\circ} \mathrm{C}$ as judged from the $100 \% \mathrm{NO}$ conversion for the fresh catalyst. For the HTA sample, however, SCR selectivity starts to decrease at $\sim 370{ }^{\circ} \mathrm{C}$. The substantially higher activities for the HTA sample in fast SCR at low-temperatures found for Fe/SSZ-13 (Fig. 7(b)), are not evident for the $\mathrm{Cu} / \mathrm{SSZ}-13$ samples. 
Fig. 9(c) presents $\mathrm{N}_{2} \mathrm{O}$ formation during standard SCR in the temperature-programmed reaction measurements on the fresh and HTA Cu/SSZ-13 catalysts. For the fresh catalyst, $\mathrm{N}_{2} \mathrm{O}$ formation is barely detectable (upper panel) while for the HTA sample, $\mathrm{N}_{2} \mathrm{O}$ formation above $\sim 150{ }^{\circ} \mathrm{C}$ is clearly evident especially at high $\left(>450{ }^{\circ} \mathrm{C}\right)$ temperatures, and a local maximum is found at $\sim 250{ }^{\circ} \mathrm{C}$. The $\mathrm{N}_{2} \mathrm{O}$ formation profiles completely overlap during the heating and cooling steps. Note again that $\mathrm{N}_{2} \mathrm{O}$ formation is barely detectable for both fresh and HTA Fe/SSZ-13 samples in standard SCR, in contrast to the case just presented for HTA Cu/SSZ-13. Fig. 9(d) displays the more complex $\mathrm{N}_{2} \mathrm{O}$ formation behavior during fast $\mathrm{SCR}$ reactions. $\mathrm{N}_{2} \mathrm{O}$ formation, via decomposition of deposited $\mathrm{NH}_{4} \mathrm{NO}_{3}\left(\sim 250-350{ }^{\circ} \mathrm{C}\right)$, is only evident during the heating step and, for both samples, the yields are similar. Quasi steady-state $\mathrm{N}_{2} \mathrm{O}$ formation yields on the HTA sample, on the other hand, appear to be higher than those for the fresh sample at all temperatures.

Fig. 10(a) depicts TPD results following temperature-programmed standard SCR reactions. For both fresh (upper panel) and HTA (lower panel) samples, no $\mathrm{NO}_{\mathrm{x}}$ desorption is observed. On the fresh sample, $\mathrm{NH}_{3}$ desorbs in two states: a lower-temperature state centered at $\sim 350{ }^{\circ} \mathrm{C}$ due to $\mathrm{NH}_{3}$ desorption from Lewis acid sites (the majority of which are $\mathrm{Cu}$ sites), and a high-temperature peak centered at $\sim 480{ }^{\circ} \mathrm{C}$ is due to $\mathrm{NH}_{3}$ desorption from Brønsted acid sites. Interestingly, high-temperature $\mathrm{NH}_{3}$ desorption from the HTA sample is essentially eliminated while a concurrent enhancement in low-temperature $\mathrm{NH}_{3}$ desorption is evident. For $\mathrm{H}_{2} \mathrm{O}$ desorption, both samples display a low-temperature state below $\sim 200{ }^{\circ} \mathrm{C}$ due to desorption of relatively weakly bound $\mathrm{H}_{2} \mathrm{O}$. Both samples also present a weaker desorption state at $\sim 300{ }^{\circ} \mathrm{C}$. The origin for this state will be discussed below. Fig. 10(b) presents TPD results after fast SCR. Similar to Fe/SSZ-13 catalysts (Fig. 8(b)), multiple NO $_{\mathrm{x}}$ desorption states are observed. NO and $\mathrm{NO}_{2}$ primarily desorb at $\sim 220{ }^{\circ} \mathrm{C}$, and $\mathrm{N}_{2} \mathrm{O}$ desorbs at $\sim 220,280$ and $310{ }^{\circ} \mathrm{C}$. For the fresh 
sample, the $\sim 280{ }^{\circ} \mathrm{C}$ state appears to be the strongest. In contrast for the HTA sample, this latter peak becomes less resolved and the $\sim 310^{\circ} \mathrm{C}$ state dominates. It is also interesting to note that the $310{ }^{\circ} \mathrm{C}$ peak is absent for the Fe/SSZ-13 samples. The lineshapes for the $\mathrm{H}_{2} \mathrm{O}$ profiles obtained from fresh and HTA Cu/SSZ-13 are similar to those for $\mathrm{N}_{2} \mathrm{O}$. As mentioned earlier, $\mathrm{H}_{2} \mathrm{O}$ desorption provides a good measure of $\mathrm{NH}_{4} \mathrm{NO}_{3}$ deposition. The difference in the amounts of $\mathrm{NH}_{4} \mathrm{NO}_{3}$ deposited on the fresh and HTA samples prior to TPD seem rather marginal. This contrasts with case for the Fe/SSZ-13 catalysts (Fig. 8(b)), where much less $\mathrm{NH}_{4} \mathrm{NO}_{3}$ deposition is found on the HTA sample.

Although SSZ-13 in the $\mathrm{H}$ form only has limited activities in standard SCR, it indeed displays considerable reactivity for fast SCR. For this reason, we also carried out temperatureprogrammed fast SCR reactions on the parent H/SSZ-13. Fig. 11(a) presents gas outlet concentrations for various reactant and product gases as a function of time, where data are collected in the same way as those shown in Fig. 6(b). Judged from $\mathrm{NO}$ and $\mathrm{NH}_{3}$ outlet concentrations, it is quite clear that H/SSZ-13 indeed displays considerable reactivity for fast SCR; however, it is less active than any of the $\mathrm{Cu}$ and Fe loaded samples. Another apparent difference is significant $\mathrm{N}_{2} \mathrm{O}$ generation between 200 and $300{ }^{\circ} \mathrm{C}$ that is observed during both ramp up and ramp down portions of the experiment. Primarily, the $\mathrm{N}_{2} \mathrm{O}$ released from H/SSZ-13 in this temperature window is likely due to $\mathrm{NH}_{4} \mathrm{NO}_{3}$ decomposition. Especially for the cooling step, this $\mathrm{N}_{2} \mathrm{O}$ production is not seen on any of the $\mathrm{Cu}$ and $\mathrm{Fe}$ loaded samples, demonstrating that in the presence of $\mathrm{Cu}$ and $\mathrm{Fe}$ cationic species, deposited $\mathrm{NH}_{4} \mathrm{NO}_{3}$ can undergo other reactions during the ramping steps as will be discussed in more detail below. Also note that between 400 and $500{ }^{\circ} \mathrm{C}, \mathrm{NO}_{2}$ outlet concentrations resemble a mirror image of $\mathrm{NO}$ ones demonstrating some $\mathrm{NO}_{2}$ conversion to NO. Because of the high temperatures at which this occurs, it is likely a consequence of thermodynamics rather than catalytic kinetics. Fig. 11(b) presents NO 
conversions as a function of temperature during the heating and cooling steps. Some extra NO conversion is found at the onset of the heating step, similar to that found for fresh Fe/SSZ-13 (Fig. 7(b), upper panel). Between 200 to $400{ }^{\circ} \mathrm{C}$, "normal" hysteresis is observed where NO conversions are slightly higher during the cooling step. Above $\sim 400{ }^{\circ} \mathrm{C}$, the nominal NO conversions decrease that, as just mentioned, may be a consequence of the thermodynamic equilibrium for $\mathrm{NO}$ and $\mathrm{NO}_{2}$. Fig. 11(c) plots the TPD results obtained after reaction. NO desorption is barely detectable, while small amounts of $\mathrm{NO}_{2}$ desorb at $\sim 230{ }^{\circ} \mathrm{C} . \mathrm{N}_{2} \mathrm{O}$ and $\mathrm{H}_{2} \mathrm{O}$ desorb in two states at $\sim 220$ and $280{ }^{\circ} \mathrm{C}$. Note that for each of these two states, the $\mathrm{H}_{2} \mathrm{O}$ signal intensity is roughly two times that of $\mathrm{N}_{2} \mathrm{O}$. Finally, $\mathrm{NH}_{3}$ predominately desorbs from Brønsted acid sites with slightly higher yields than those from $\mathrm{Fe}$ and $\mathrm{Cu}$ loaded fresh samples.

\section{Discussion}

\subsection{Reactions involved in $\mathrm{SCR}, \mathrm{NO} / \mathrm{NH}_{3}$ oxidation and TPD}

Chemistry involved in $\mathrm{NH}_{3}-\mathrm{SCR}$ is rather complicated. Not only are the elementary reaction steps, especially the ones that are rate-limiting, not fully understood, even the global pathways are complex enough that an extensive reaction network is generally required for a detailed description [33]. In the present study, global reactions involved are qualitatively described below, mainly to serve as the basis for discussions of the similarities and differences between $\mathrm{Cu}$ - and $\mathrm{Fe} / \mathrm{SSZ}-13$ catalysts.

$\mathrm{NH}_{3}-\mathrm{SCR}$ reactions, depending on $\mathrm{NO} / \mathrm{NO}_{\mathrm{x}}$ ratios, are generally classified as standard, fast, and $\mathrm{NO}_{2}-\mathrm{SCR}$, with global pathways listed in equations 1-3, respectively:

$$
\begin{aligned}
& 4 \mathrm{NO}+4 \mathrm{NH}_{3}+\mathrm{O}_{2}=4 \mathrm{~N}_{2}+6 \mathrm{H}_{2} \mathrm{O}(\text { standard SCR }) \\
& \mathrm{NO}+\mathrm{NO}_{2}+2 \mathrm{NH}_{3}=2 \mathrm{~N}_{2}+3 \mathrm{H}_{2} \mathrm{O}(\text { fast SCR }) \\
& 6 \mathrm{NO}_{2}+8 \mathrm{NH}_{3}=7 \mathrm{~N}_{2}+12 \mathrm{H}_{2} \mathrm{O}\left(\mathrm{NO}_{2}-\mathrm{SCR}\right)
\end{aligned}
$$


Among the three pathways, the $\mathrm{NO}_{2}-\mathrm{SCR}$ is the least well-documented. Grossale et al. [27, 34] applied transient reaction analysis to understand this reaction on a commercial Fe/zeolite, and proposed a mechanism where surface nitrates are first formed by $\mathrm{NO}_{2}$ disproportionation, followed by their catalytic reduction to nitrogen by ammonia:

$$
\begin{aligned}
& 6 \mathrm{NO}_{2}+3 \mathrm{H}_{2} \mathrm{O}=3 \mathrm{HONO}+3 \mathrm{HNO}_{3} \\
& 3 \mathrm{HONO}+3 \mathrm{NH}_{3}=3 \mathrm{~N}_{2}+6 \mathrm{H}_{2} \mathrm{O} \\
& 3 \mathrm{HNO}_{3}+5 \mathrm{NH}_{3}=4 \mathrm{~N}_{2}+9 \mathrm{H}_{2} \mathrm{O}
\end{aligned}
$$

Note that because of the much higher thermal stabilities of $\mathrm{NH}_{4} \mathrm{NO}_{3}$ as compared to $\mathrm{NH}_{4} \mathrm{NO}_{2}$, reaction (6) can be further divided to reactions (7) and (8):

$$
\begin{aligned}
& \mathrm{NH}_{3}+\mathrm{HNO}_{3}=\mathrm{NH}_{4} \mathrm{NO}_{3} \\
& 3 \mathrm{NH}_{4} \mathrm{NO}_{3}+2 \mathrm{NH}_{3}=4 \mathrm{~N}_{2}+9 \mathrm{H}_{2} \mathrm{O}
\end{aligned}
$$

Although standard and fast SCR are very selective, numerous studies have realized the correlation between $\mathrm{NO}_{2}$-SCR and $\mathrm{N}_{2} \mathrm{O}$ formation; and literature has documented very well that ammonium nitrate can decompose to generate $\mathrm{N}_{2} \mathrm{O}$ :

$$
\mathrm{NH}_{4} \mathrm{NO}_{3}=\mathrm{N}_{2} \mathrm{O}+2 \mathrm{H}_{2} \mathrm{O}
$$

In this sense, $\mathrm{N}_{2} \mathrm{O}$ formation might be regarded as a "fingerprint" for $\mathrm{NO}_{2}-\mathrm{SCR}$. Moreover, in the presence of a standard SCR feed, Tronconi and coworkers [35, 36] have discovered a so-called “enhanced SCR" pathway important even at relatively low temperatures (e.g., $200{ }^{\circ} \mathrm{C}$ ) on Fe/zeolites:

$$
2 \mathrm{NO}+2 \mathrm{NH}_{3}+\mathrm{NH}_{4} \mathrm{NO}_{3}=2 \mathrm{~N}_{2}+5 \mathrm{H}_{2} \mathrm{O}
$$

This "enhanced SCR" may be a result of another important reaction involving $\mathrm{NH}_{4} \mathrm{NO}_{3}$, that being its reduction by NO:

$$
\mathrm{NH}_{4} \mathrm{NO}_{3}+\mathrm{NO}=\mathrm{NO}_{2}+\mathrm{N}_{2}+2 \mathrm{H}_{2} \mathrm{O}
$$


Other critical reactions, that are closely related with $\mathrm{NH}_{3}-\mathrm{SCR}$, are the oxidations of $\mathrm{NO}$ and $\mathrm{NH}_{3} . \mathrm{Cu}-$ and $\mathrm{Fe} /$ zeolites catalyze these reactions rather selectively, and their reaction pathways are likely to be as complex as $\mathrm{NH}_{3}-\mathrm{SCR}$. On $\mathrm{Cu}$ - and $\mathrm{Fe} /$ zeolite catalysts, $\mathrm{NO}$ is selectively oxidized to $\mathrm{NO}_{2}$ :

$$
2 \mathrm{NO}+\mathrm{O}_{2}=2 \mathrm{NO}_{2}
$$

Possible minor side reactions include $\mathrm{NO}$ decomposition to $\mathrm{N}_{2}$ and $\mathrm{O}_{2}$, and nitrate formation due, as discussed above, to $\mathrm{NO}_{2}$ disproportionation. $\mathrm{NH}_{3}$ is typically selectively oxidized to $\mathrm{N}_{2}$ by $\mathrm{Cu}$ and $\mathrm{Fe} /$ zeolite catalysts:

$$
4 \mathrm{NH}_{3}+3 \mathrm{O}_{2}=2 \mathrm{~N}_{2}+6 \mathrm{H}_{2} \mathrm{O}
$$

For this reaction, side reactions include $\mathrm{NH}_{3}$ oxidation to $\mathrm{NO}, \mathrm{NO}_{2}$ or $\mathrm{N}_{2} \mathrm{O}$. These are typically very minor and only occur at relatively high temperatures $\left(\geq 400^{\circ} \mathrm{C}\right)$.

Reactions involved in TPD comprise two categories: deposition processes occurring prior to TPD, and decomposition reactions during TPD. For standard SCR, as shown in Figs. 8(a) and 10 (a), only $\mathrm{NH}_{3}$ and $\mathrm{H}_{2} \mathrm{O}$ desorption is detected $\left(\mathrm{N}_{2}\right.$ desorption cannot be monitored), suggesting that deposition of large amounts of $\mathrm{NH}_{4} \mathrm{NO}_{3}$ prior to TPD does not occur. For the $\mathrm{Cu} / \mathrm{SSZ}-13$ catalysts, however, $\mathrm{H}_{2} \mathrm{O}$ evolution at $\sim 300{ }^{\circ} \mathrm{C}$ does suggest small amounts of $\mathrm{NH}_{4} \mathrm{NO}_{3}$ deposition, which, during the subsequent temperature ramping, decompose according to equation (8). For fast SCR, maintaining the samples at $100{ }^{\circ} \mathrm{C}$ indeed allows large quantities of $\mathrm{NH}_{4} \mathrm{NO}_{3}$ deposition according to reactions (4) and (7). As shown in Fig. 11(c), TPD after temperature-programmed fast SCR on H/SSZ-13 is quite readily understood. The majority of $\mathrm{N}_{2} \mathrm{O}$ and $\mathrm{H}_{2} \mathrm{O}$ desorb between 200 and $300{ }^{\circ} \mathrm{C}$ and the $\mathrm{N}_{2} \mathrm{O}$ yield is approximately $50 \%$ of that for $\mathrm{H}_{2} \mathrm{O}$ demonstrating reaction (9) is the main decomposition pathway for deposited $\mathrm{NH}_{4} \mathrm{NO}_{3}$ on H/SSZ-13. Note, however, small amounts of $\mathrm{NO}_{2}$ also desorb in this temperature window perhaps suggesting another minor decomposition pathway for $\mathrm{NH}_{4} \mathrm{NO}_{3}$, notably: 


$$
\mathrm{NH}_{4} \mathrm{NO}_{3}=\mathrm{NH}_{4}^{+}+\mathrm{O}^{-}+\mathrm{NO}_{2}
$$

This pathway can be observed when a reaction occurs for $\mathrm{NH}_{4} \mathrm{NO}_{3}$ molecules associated with Brønsted acid sites (e.g., $-\mathrm{Si}-\mathrm{O}(\mathrm{H})-\mathrm{Al}-$ ). As evidenced by the higher $\mathrm{NO}_{2}$ levels in TPD shown in Figs. 8(b) and 10(b), this pathway appears to be more important for $\mathrm{Cu}-$ and Fe/SSZ-13 catalysts than on H/SSZ-13. Also from Figs. 8(b) and 10(b), $\mathrm{H}_{2} \mathrm{O}$ yields are greater than 2 times the $\mathrm{N}_{2} \mathrm{O}$ yields, especially for the fresh and HTA Fe/SSZ-13 catalysts. This indicates that some $\mathrm{H}_{2} \mathrm{O}$ must also be generated from reactions other than reaction (9). Due to the lack of NO storage, it appears likely that reaction (8), instead of reaction (10), is responsible for the formation of "extra" $\mathrm{H}_{2} \mathrm{O}$ during TPD. However, $\mathrm{N}_{2} \mathrm{O}$ evolution during the ramping steps (see, e.g., Figs. 7(c) and 9(d)) is substantially less than during TPD suggesting that, in the presence of SCR reactants, deposited $\mathrm{NH}_{4} \mathrm{NO}_{3}$ primarily undergoes reactions (8) and (10) instead of decomposition (i.e., reaction (9)).

\subsection{Comparison between reactivity of $\mathrm{Cu}$ and $\mathrm{Fe}$ active sites}

In the introduction section, literature findings for comparative SCR activities between $\mathrm{Cu}$ - and Fe/zeolites are summarized [26-30]: (1) Fe/zeolites display strong $\mathrm{NH}_{3}$ inhibition effects at low temperatures; (2) Cu/zeolites are much less sensitive to $\mathrm{NO}_{2} / \mathrm{NO}_{\mathrm{x}}$ ratios of the reactant feed; and (3) Fe/zeolites are typically less selective in $\mathrm{N}_{2} \mathrm{O}$ formation, especially at $\mathrm{NO}_{2} / \mathrm{NO}_{\mathrm{x}}$ ratios $\leq 0.5$. In the present study, all of these findings are reproduced on our $\mathrm{Cu}-$ and Fe/SSZ-13 catalysts. For example, SCR reaction data shown in Fig. 1 are readily explained by $\mathrm{NH}_{3}$ inhibition of Fe/SSZ-13. This inhibition effect can be understood in two ways: (1) $\mathrm{NH}_{3}$ binds with $\mathrm{Fe}$ centers strongly at low temperatures thereby preventing $\mathrm{NO}_{\mathrm{x}}$ coordination with $\mathrm{Fe}$; or (2) Fe ions are 'trapped' in the +2 oxidation state (Fe(II)) due to reduction by $\mathrm{NH}_{3}$ such that $\mathrm{Fe}(\mathrm{III}) / \mathrm{Fe}(\mathrm{II})$ redox cannot proceed for NO oxidation at low temperatures. The fact that fast SCR proceeds on Fe/zeolites at rather low temperatures strongly suggests that explanation (2) is more 
likely. As to the insensitivity of $\mathrm{NO}_{2} / \mathrm{NO}_{\mathrm{x}}$ ratios for SCR rates on $\mathrm{Cu}$ /zeolites, Fig. 9 provides a good example to demonstrate that "fast" SCR does not proceed any faster than standard SCR on $\mathrm{Cu} / \mathrm{SSZ}-13$. Furthermore, due to $\mathrm{NH}_{4} \mathrm{NO}_{3}$ inhibition (which will be discussed below), fast SCR can even proceed slower than standard SCR. Although not fully understood yet, these results do strongly suggest that standard SCR proceeds via a mechanism distinct from fast SCR; specifically, $\mathrm{NO}_{2}$ does not necessarily have to be involved as a reaction intermediate in a standard SCR mechanism [18, 37-39]. Comparative $\mathrm{N}_{2} \mathrm{O}$ formation during SCR on $\mathrm{Cu}-$ and Fe/zeolites is also an interesting and important subject that will be taken up below.

For the fresh $\mathrm{Cu}$ - and Fe/SSZ-13 samples, the key catalytic sites are extra-framework cationic species. However, complexity with respect to the active species is evident when the fresh samples are hydrothermally aged. A key feature for hydrothermal aging is dealumination and the consequent $\mathrm{Cu} / \mathrm{Fe}$ ion migration from the now missing zeolitic ion exchange sites. To better understand comparative dealumination during aging, Fig 12 presents ${ }^{27} \mathrm{Al}$ NMR of the fresh and HTA Cu- and Fe/SSZ-13 samples. Details on NMR data collection can be found elsewhere [22]. By comparing normalized framework $\mathrm{Al}\left(\mathrm{Al}_{\mathrm{f}}\right)$ signal intensities, both HTA samples dealuminate substantially, and HTA Fe/SSZ-13 dealuminates even more severely. The NMR results are fully consistent with the $\mathrm{NH}_{3}$-TPD data shown in Figs. 8 and 10. In particular from $\mathrm{NH}_{3}$-TPD, HTA Fe/SSZ-13 loses most of the $\mathrm{NH}_{3}$ chemisorption capacity while HTA $\mathrm{Cu} / \mathrm{SSZ}-13$ mainly weakens this capacity. Significantly, these results also indicate that tetrahedral Al sites from Fe/SSZ-13 do not convert to extra-framework Lewis acid sites after aging while they apparently do for aged $\mathrm{Cu} / \mathrm{SSZ}-13$. In our recent study, CO/NO titration FTIR results suggest $\mathrm{FeAlO}_{\mathrm{x}}$ formation in aged Fe/SSZ-13 [25]. This explains, in part, the lack of Lewis acidity in aged Fe/SSZ-13. 
It is not clear why HTA Fe/SSZ-13 dealuminates more than Cu/SSZ-13 at identical aging conditions. One plausible explanation is that Fe(III) can adopt tetrahedral coordination and get into the zeolite framework to replace $\mathrm{Al}$, while this is not expected for $\mathrm{Cu}(\mathrm{II})$. However, there is not yet strong evidence to prove that this is occurring even for Fe. In any case, a portion of $\mathrm{Fe}^{3+} / \mathrm{Cu}^{2+}$ ions will have to migrate from charge-balancing cationic sites upon dealumination. In HTA Fe/SSZ-13, CO/NO titration FTIR suggests $\mathrm{FeAlO}_{\mathrm{x}}$ and $\mathrm{FeO}_{\mathrm{x}}$ formation [25]; while for $\mathrm{HTA} \mathrm{Cu} / \mathrm{SSZ}-13, \mathrm{CuO}_{\mathrm{x}}$ formation is expected. Because of the need to activate $\mathrm{O}_{2}$, it is generally agreed that only $\mathrm{Cu} / \mathrm{Fe}$ ion dimers or clusters catalyze $\mathrm{NO}$ and $\mathrm{NH}_{3}$ oxidation reactions [23, 40, 41]. For $\mathrm{Cu} / \mathrm{Fe}$ oxide clusters, one expects that their activity decreases with increasing cluster size due to decreased surface site exposure. As shown in Figs. 3 and 4, Fe/SSZ-13 markedly loses oxidation activity upon aging. From the discussion immediately above, this can be rationalized by the depletion of active Fe ion dimers during aging. Note that Branderberger et al. [42] also found a decrease in $\mathrm{NH}_{3}$ oxidation reactivity upon hydrothermal aging of Fe/ZSM-5. On the other hand, Cu/SSZ-13 gains NO oxidation activity (Fig. 3), loses low-temperature ( $\leq$ $300{ }^{\circ} \mathrm{C}$ ) but gains high-temperature $\mathrm{NH}_{3}$ oxidation activity (Fig. 4) upon aging. This, in general, can be rationalized by the formation of $\mathrm{CuO}_{x}$ clusters during aging, which are highly active for oxidation reactions. Note, however, that $\mathrm{NH}_{3}$ oxidation kinetics shown in Fig. 4 are quite complex and may be better understood by invoking a temperature-dependent transition of active centers [23]. Finally for standard SCR, steady-state kinetics illustrated in Figs. 1 and 2 clearly show how $\mathrm{NH}_{3}$ oxidation activities affect high-temperature SCR selectivities, explaining why $\mathrm{Cu} / \mathrm{SSZ}-13$ loses high-temperature SCR selectivities upon aging while Fe/SSZ-13 becomes more selective at high-temperatures after hydrothermal aging.

\subsection{Hysteresis and roles of $\mathrm{NH}_{4} \mathrm{NO}_{3}$ in temperature-programmed reactions}


In temperature-programmed standard SCR, "normal" weak hysteresis in NO conversion is found (Figs. 7(a) and 9(a)) where NO conversions are slightly higher during the cooling step. This can be explained by a weak " $\mathrm{NH}_{3}$ inhibition" effect; in essence, at the same reaction temperature in the regime where such hysteresis is found, the only difference expected between the heating and cooling steps are small variations in the amounts of stored $\mathrm{NH}_{3}$. During the heating step, higher $\mathrm{NH}_{3}$ concentrations on $\mathrm{Cu} / \mathrm{Fe}$ centers could cause $\mathrm{Cu} / \mathrm{Fe}$ centers to be more reduced and, thus, slightly less active. An exception to this "normal" hysteresis occurs in the temperature window where stored $\mathrm{NH}_{3}$ starts to be desorbed from Brønsted acid sites (e.g., region from "b" to "c" in Fig. 7(a)). In this case, stored $\mathrm{NH}_{3}$ molecules themselves become reactive causing transient higher NO conversions in the heating step.

The much more pronounced hysteresis found during fast SCR (Figs. 7(b) and 9(b)) comes from " $\mathrm{NH}_{4} \mathrm{NO}_{3}$ inhibition", and arguments from a redox mechanism perspective given above no longer apply. For example, in an operando X-ray absorption spectroscopy (XAS) study by Kispersky et al. [10], the authors found that $\mathrm{Cu}$ in $\mathrm{Cu} / \mathrm{SSZ}-13$ permanently stays as $\mathrm{Cu}$ (II) under fast SCR conditions. The strongest evidence for " $\mathrm{NH}_{4} \mathrm{NO}_{3}$ inhibition" comes from a comparison in NO conversions between fresh and HTA Fe/SSZ-13 (Fig. 7(b)), and the TPD results following reaction (Fig. 8(b)). Interestingly, HTA Fe/SSZ-13 shows substantially enhanced lowtemperature performance relative to fresh Fe/SSZ-13 due to much reduced $\mathrm{NH}_{4} \mathrm{NO}_{3}$ inhibition. For the fresh and HTA Cu/SSZ-13 samples (Fig. 9(b)), difference in low-temperature fast SCR performance between fresh and aged catalysts is much less dramatic as compared to the Fe/SSZ-13 samples. Indeed, TPD data shown in Fig. 10(b) indicates that the amounts of $\mathrm{NH}_{4} \mathrm{NO}_{3}$ deposition are rather similar for fresh and HTA Cu/SSZ-13. This is consistent with the fact that HTA Cu/SSZ-13 dealuminates much less than HTA Fe/SSZ-13 (Fig. 12). These findings are important in elucidating the $\mathrm{NH}_{4} \mathrm{NO}_{3}$ deposition mechanism shown in equation (7). 
Based on the fact that acidity (Lewis and Brønsted alike) apparently promotes $\mathrm{NH}_{4} \mathrm{NO}_{3}$ deposition, the following reactions seem likely to be involved:

$$
\begin{aligned}
& \mathrm{H}^{+}+\mathrm{NH}_{3}=\mathrm{NH}_{4}^{+} \\
& \mathrm{NH}_{4}^{+}+\mathrm{HNO}_{3}=\mathrm{NH}_{4} \mathrm{NO}_{3}+\mathrm{H}^{+} \\
& \mathrm{L}^{\cdots} \mathrm{NH}_{3}+\mathrm{HNO}_{3}=\mathrm{NH}_{4} \mathrm{NO}_{3}+\mathrm{L}(\mathrm{L} \text { represents Lewis acid })
\end{aligned}
$$

From the temperature programmed fast SCR reaction results, it is also important to note the difficulty of conducting low-temperature steady-state fast SCR measurements with Chabazite based catalysts. For example from Fig. 9(b), depending on whether the catalyst is relatively clean or has an $\mathrm{NH}_{4} \mathrm{NO}_{3}$ deposit, $\mathrm{NO}$ conversions can change from nearly $100 \%$ to as low as $\sim 30 \%$ at a reaction temperature of $200{ }^{\circ} \mathrm{C}$. This indicates that at temperatures where net $\mathrm{NH}_{4} \mathrm{NO}_{3}$ deposition exists, a steady-state is difficult to reach. This is the primary reason why fast-SCR kinetics are only conducted in a temperature-programmed mode here.

\subsection{Application potentials for Fe/SSZ-13}

At temperatures for normal diesel engine on-road operations (i.e., 200 to $300{ }^{\circ} \mathrm{C}$ ), $\mathrm{Cu} / \mathrm{SSZ}-13$ provides much better performance than Fe/SSZ-13. Therefore Fe/SSZ-13 alone is insufficient as a good SCR catalyst for transportation needs. However, as displayed in Fig. 5, the combination of the two catalysts (in the form of a physical mixture here) indeed provides more stable performance and reduced $\mathrm{N}_{2} \mathrm{O}$ formation at high temperatures. High-temperature $\mathrm{N}_{2} \mathrm{O}$ generation by aged $\mathrm{Cu} / \mathrm{SSZ}-13$ is mainly due to non-selective $\mathrm{NH}_{3}$ oxidation:

$$
2 \mathrm{NH}_{3}+2 \mathrm{O}_{2}=\mathrm{N}_{2} \mathrm{O}+3 \mathrm{H}_{2} \mathrm{O}
$$

The possibility for $\mathrm{N}_{2} \mathrm{O}$ reduction by Fe/SSZ-13, on the other hand, can be understood from the following $\mathrm{N}_{2} \mathrm{O}-\mathrm{SCR}$ pathway:

$$
3 \mathrm{~N}_{2} \mathrm{O}+2 \mathrm{NH}_{3}=4 \mathrm{~N}_{2}+3 \mathrm{H}_{2} \mathrm{O}
$$


Results shown in Fig. 5(b) indicate that Fe/SSZ-13 is a much better catalyst than Cu/SSZ-13 in catalyzing this latter high-temperature reaction. The synergy for the mixed catalyst in this regard, therefore, is that some $\mathrm{N}_{2} \mathrm{O}$ generated by $\mathrm{Cu} / \mathrm{SSZ}-13$ is consumed by Fe/SSZ-13.

The combination of $\mathrm{Cu}$ and $\mathrm{Fe} /$ zeolites as a concept has existed for several years and very detailed work, for example, the mass ratio and positioning in a layered coating for the two catalysts, has been carried out previously [26, 29, 30]. Several advantages for a combined catalyst are envisioned: (1) performance at transient high-temperature conditions, e.g., during combustion of trapped particulate matter; (2) for conditions when the $\mathrm{NO}_{2}$ content in the feed is elevated; and (3) in the presence of sulfur poisoning. Overall, for this working concept, Fe/SSZ-13 can certainly be considered as one component because of its excellent hydrothermal stability, and especially its low selectivity for $\mathrm{N}_{2} \mathrm{O}$ formation [25].

\section{Conclusions}

(1) For standard SCR, both fresh and aged Cu/SSZ-13 catalysts show much better lowtemperature performance than Fe/SSZ-13 catalysts, which can be explained by an increased sensitivity to $\mathrm{NH}_{3}$-inhibition by $\mathrm{Fe} / \mathrm{SSZ}-13$. The nature of this inhibition may be related to $\mathrm{Fe}(\mathrm{III})$ reduction to $\mathrm{Fe}(\mathrm{II})$ by $\mathrm{NH}_{3}$.

(2) During hydrothermal aging, both catalysts undergo dealumination but Fe/SSZ-13 dealuminates more severely. One plausible explanation for maintenance of the zeolite in this case is that Fe can replace framework Al.

(3) For aged catalysts, $\mathrm{Cu} / \mathrm{SSZ}-13$ gains oxidation activity due to formation of $\mathrm{CuO}_{\mathrm{x}}$. However, Fe/SSZ-13 loses oxidation activity even though formation of $\mathrm{FeO}_{\mathrm{x}}$ clusters and $\mathrm{Fe}_{\mathrm{AlO}}$ species also occurs. Because of such differences, aged Cu/SSZ-13 loses, while Fe/SSZ-13 maintains high-temperature SCR selectivities. As such, a physical mixture of aged catalysts provides stable 
SCR performance in a wide temperature range, and is also able to decrease $\mathrm{N}_{2} \mathrm{O}$ formation at high reaction temperatures. This suggests that Fe/SSZ-13 can be used as a cocatalyst for $\mathrm{Cu} / \mathrm{SSZ}-13$ for transportation applications.

(4) During temperature-programmed SCR reactions, weak hysteresis is found during standard SCR due to $\mathrm{NH}_{3}$ inhibition. In this case, $\mathrm{NO}$ conversions during the cooling step are slightly higher than during the heating step except in the temperature window where $\mathrm{NH}_{3}$ molecules are released by Brønsted acid sites. For fast SCR, hysteresis caused by $\mathrm{NH}_{4} \mathrm{NO}_{3}$ inhibition is much more significant. $\mathrm{NH}_{4} \mathrm{NO}_{3}$ deposition is considerably enhanced by Brønsted and Lewis acidity of the catalysts. $\mathrm{NH}_{4} \mathrm{NO}_{3}$ inhibition also makes low-temperature steady-state fast $\mathrm{SCR}$ reaction measurements challenging.

\section{Acknowledgements}

The authors gratefully acknowledge the US Department of Energy (DOE), Energy Efficiency and Renewable Energy, Vehicle Technologies Office for the support of this work. The research described in this paper was performed at the Environmental Molecular Sciences Laboratory (EMSL), a national scientific user facility sponsored by the DOE's Office of Biological and Environmental Research and located at Pacific Northwest National Laboratory (PNNL). PNNL is operated for the US DOE by Battelle. Discussions with Drs. A. Yezerets, K. Kamasamudram, J.H. Li, N. Currier and J.Y. Luo from Cummins, Inc., and H.Y. Chen and H. Hess from JohnsonMatthey are greatly appreciated.

\section{References}

[1] K. Kamasamudram, N.W. Currier, X. Chen, A. Yezerets, Catal. Today 151 (2010) 212.

[2] J.H. Kwak, R.G. Tonkyn, D.H. Kim, J. Szanyi, C.H.F. Peden, J. Catal. 275 (2010) 187.

[3] D.W. Fickel, E. D’Addio, J.A. Lauterbach, R.F. Lobo, Appl. Catal. B 102 (2011) 441.

[4] S.J. Schmieg, S.H. Oh, C.H. Kim, D.B. Brown, J.H. Lee, C.H.F. Peden, D.H. Kim, Catal. Today 184 (2012) 252. 
[5] L. Wang, W. Li, G. Qi, D. Weng, J. Catal. 289 (2012) 21.

[6] J.H. Kwak, D. Tran, S.D. Burton, J. Szanyi, J.H. Lee, C.H.F. Peden, J. Catal. 287 (2012) 203.

[7] D.W. Fickel, R. F. Lobo, J. Phys. Chem. C 114 (2010) 1633.

[8] S.T. Korhonen, D.W. Fickel, R.F. Lobo, B.M. Weckhuysen, A.M. Beale, Chem. Commun. 47 (2011) 800 .

[9] U. Deka, A. Juhin, E.A. Eilertsen, H. Emerich, M.A. Green, S.T. Korhonen, B.M. Weckhuysen, A.M. Beale, J. Phys. Chem. C 116 (2012) 4809.

[10] V.F. Kispersky, A.J. Kropf, F.H. Ribeiro, J.T. Miller, Phys. Chem. Chem. Phys., 14 (2012) 2229.

[11] J.H. Kwak, D. Tran, J. Szanyi, C.H.F. Peden, J.H. Lee, Catal. Lett. 142 (2012) 295.

[12] J.H. Kwak, H. Zhu, J.H. Lee, C.H.F. Peden, J. Szanyi, Chem. Commun. 48 (2012) 4758.

[13] R. Martínez-Franco, M. Moliner, C. Franch, A. Kustov, A. Corma, Appl. Catal. B 127 (2012) 273.

[14] J.-S. McEwen, T. Anggara, W.F. Schneider, V.F. Kispersky, J.T. Miller, W.N. Delgass, F.H. Ribeiro, Catal. Today 184 (2012) 129.

[15] J. Wang, T. Yu, X. Wang, G. Qi, J. Xue, M. Shen, W. Li, Appl. Catal. B 127 (2012) 137.

[16] F. Gao, E.D. Walter, E.M. Karp, J. Luo, R.G. Tonkyn, J.H. Kwak, J. Szanyi, C.H.F. Peden, J. Catal. $300(2013) 20$.

[17] F. Giordanino, P.N.R. Vennestrøm, L.F. Lundegaard, F.N. Stappen, S. Mossin, P. Beato, S. Bordiga, C. Lamberti, Dalton Trans. 42 (2013) 12741.

[18] J.H. Kwak, J.H. Lee, S.D. Burton, A.S. Lipton, C.H.F. Peden, J. Szanyi, Angew. Chem. Int. Ed. 53 (2013) 9985.

[19] J. Szanyi, J.H. Kwak, H. Zhu, C.H.F. Peden, Phys. Chem. Chem. Phys. 15 (2013) 2368.

[20] H. Zhu, J.H. Kwak, C.H.F. Peden, J. Szanyi, Catal. Today 205 (2013) 16.

[21] J.H. Kwak, T. Varga, C.H.F. Peden, F. Gao, J.C. Hanson, J. Szanyi, J. Catal. 314 (2014) 83.

[22] F. Gao, E.D. Walter, N.M. Washton, J. Szanyi, C.H.F. Peden, ACS Catal. 3 (2013) 2083.

[23] F. Gao, E.D. Walter, M. Kollar, Y. Wang, J. Szanyi, C.H.F. Peden, J. Catal. 319 (2014) 1.

[24] R. Zhang, J.-S. McEwen, M. Kollár, F. Gao, Y. Wang, J. Szanyi, C.H.F. Peden, ACS Catal. in press. DOI: $10.1021 / \mathrm{cs} 500563 \mathrm{~s}$.

[25] F. Gao, M. Kollár, R.K. Kukkadapu, N.M. Washton, Y. Wang, J. Szanyi, C.H.F. Peden, Appl. Catal. B 164 (2015) 407.

[26] O. Krocher, M. Elsener, Ind. Eng. Chem. Res. 47 (2008) 8588.

[27] A. Grossale, I. Nova, E. Tronconi, D. Chatterjee, M. Weibel, Top. Catal. 52 (2009) 1837. 
[28] M. Colombo, I. Nova, E. Tronconi, Catal. Today 151 (2010) 223.

[29] P.S. Metkar, M.P. Harold, V. Balakotaiah, Appl. Catal. B 111-112 (2012) 67.

[30] P.S. Metkar, M.P. Harold, V. Balakotaiah, Chem. Eng. Sci. 87 (2013) 51.

[31] S. Malmberg, M. Votsmeier, J. Gieshoff, N. Söger, L. Mußmann, A. Schuler, A. Drochner, Top. Catal. 42-43 (2007) 33.

[32] I. Nova, M. Colombo, E. Tronconi, V. Schmeisser, M. Weibel, SAE Technical paper 2011-01-1319.

[33] S. Brandenberger, O. Kröcher, A. Tissler, R. Althoff, Catal. Rev. 50 (2008) 492.

[34] A. Grossale, I. Nova, E. Tronconi, Catal. Lett. 130 (2009) 525.

[35] P. Forzatti, I. Nova, E. Tronconi, Angew. Chem. Int. Ed. 48 (2009) 8366.

[36] P. Forzatti, I. Nova, E. Tronconi, Ind. Eng. Chem. Res. 49 (2010) 10386.

[37] F. Gao, J.H. Kwak, J. Szanyi, C.H.F. Peden, Top. Catal. 56 (2013) 1441.

[38] M.P. Ruggeri, I. Nova, E. Tronconi, Top. Catal. 56 (2013) 109.

[39] I. Ellmers, R.P. Vélez, U. Bentrup, A. Brückner, W. Grünert, J. Catal. 311 (2014) 199.

[40] S. Brandenberger, O. Kröcher, A. Tissler, R. Althoff, Appl. Catal. B 95 (2010) 348.

[41] A.A. Verma, S.A. Bates, T. Anggara, C. Paolucci, A.A. Parekh, K. Kamasamudram, A. Yezerets, J.T. Miller, W.N. Delgass, W.F. Schneider, F.H. Ribeiro, J. Catal. 312 (2014) 179.

[42] S. Brandenberger, O. Kröcher, M. Casapu, A. Tissler, R. Althoff, Appl. Catal. B 101 (2011) 649. 


\section{Figure Captions}

Figure $1 \mathrm{NO} / \mathrm{NH}_{3}$ conversions as a function of temperature during standard SCR for the fresh $\mathrm{Cu}$ - and Fe/SSZ-13 samples. Reactant feed contains $350 \mathrm{ppm} \mathrm{NO}, 350 \mathrm{ppm} \mathrm{NH}, 14 \% \mathrm{O}_{2}, 2.5 \%$ $\mathrm{H}_{2} \mathrm{O}$ balanced with $\mathrm{N}_{2}$ at a GHSV of $200,000 \mathrm{~h}^{-1}$.

Figure $2 \mathrm{NO} / \mathrm{NH}_{3}$ conversions as a function of temperature during standard SCR for the HTA (a) Fe/SSZ-13, and (b) Cu/SSZ-13 samples. Reactant feed contains $350 \mathrm{ppm} \mathrm{NO}, 350 \mathrm{ppm} \mathrm{NH}_{3}$, $14 \% \mathrm{O}_{2}, 2.5 \% \mathrm{H}_{2} \mathrm{O}$ balanced with $\mathrm{N}_{2}$ at a GHSV of $200,000 \mathrm{~h}^{-1}$.

Figure 3 NO conversions as a function of temperature during NO oxidation for the (a) fresh, and (b) HTA Cu- and Fe/SSZ-13 samples. Reactant feed contains 350 ppm NO, $14 \% \mathrm{O}_{2}, 2.5 \% \mathrm{H}_{2} \mathrm{O}$ balanced with $\mathrm{N}_{2}$ at a GHSV of $200,000 \mathrm{~h}^{-1}$.

Figure $4 \mathrm{NH}_{3}$ conversions as a function of temperature during $\mathrm{NH}_{3}$ oxidation for the (a) fresh,

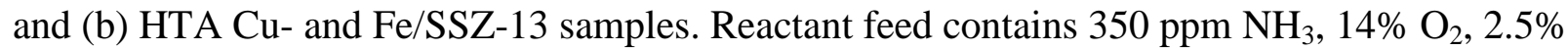
$\mathrm{H}_{2} \mathrm{O}$ balanced with $\mathrm{N}_{2}$ at a GHSV of $200,000 \mathrm{~h}^{-1}$.

Figure 5 (a) NO conversions as a function of temperature during standard SCR for the HTA $\mathrm{Cu} / \mathrm{SSZ}-13, \mathrm{Fe} / \mathrm{SSZ}-13$ and mixed (1/1) samples. Reactant feed contains 350 ppm NO, 350 ppm $\mathrm{NH}_{3}, 14 \% \mathrm{O}_{2}, 2.5 \% \mathrm{H}_{2} \mathrm{O}$ balanced with $\mathrm{N}_{2}$ at a GHSV of $200,000 \mathrm{~h}^{-1}$. (b) $\mathrm{N}_{2} \mathrm{O}$ yields as a function of temperature during the reaction on the three catalysts.

Figure 6 (a) Temperature and gas outlet concentrations as a function of time during temperatureprogrammed standard SCR for a fresh Fe/SSZ-13 catalyst. Reactant feed contains 350 ppm NO, 350 ppm $\mathrm{NH}_{3}, 14 \% \mathrm{O}_{2}, 2.5 \% \mathrm{H}_{2} \mathrm{O}$ balanced with $\mathrm{N}_{2}$ at a GHSV of $200,000 \mathrm{~h}^{-1}$. (b) Temperature and gas outlet concentrations as a function of time during temperature-programmed fast SCR on a fresh Fe/SSZ-13 catalyst. Reactant feed contains 175 ppm NO, 175 ppm NO 2,350 ppm NH $14 \% \mathrm{O}_{2}, 2.5 \% \mathrm{H}_{2} \mathrm{O}$ balanced with $\mathrm{N}_{2}$ at a GHSV of $200,000 \mathrm{~h}^{-1}$.

Figure $7 \mathrm{NO}$ conversions as a function of temperature during temperature-programmed (a) standard SCR, and (b) fast SCR for fresh (upper panel) and HTA (lower panel) Fe/SSZ-13 samples. NO conversions are calculated using data from Figs. 6 and S1. (c) $\mathrm{N}_{2} \mathrm{O}$ yields as a function of temperature during fast SCR for fresh (upper panel) and HTA (lower panel) Fe/SSZ-13 samples. 
Figure 8 Temperature-programmed desorption profiles for fresh (upper panel) and HTA (lower panel) Fe/SSZ-13 samples after (a) standard SCR and (b) fast SCR reactions.

Figure 9 NO conversions as a function of temperature during temperature-programmed (a) standard SCR, and (b) fast SCR for fresh (upper panel) and HTA (lower panel) Cu/SSZ-13 samples. NO conversions are calculated using data from Figs. S2 and $\mathrm{S} 3 . \mathrm{N}_{2} \mathrm{O}$ yields as a function of temperature for fresh (upper panel) and HTA (lower panel) Cu/SSZ-13 samples during temperature-programmed (c) standard SCR, and (d) fast SCR.

Figure 10 Temperature-programmed desorption profiles for fresh (upper panel) and HTA (lower panel) Cu/SSZ-13 samples after (a) standard SCR and (b) fast SCR reactions.

Figure 11 (a) Temperature and gas outlet concentrations as a function of time during temperature-programmed fast SCR for an H/SSZ-13 catalyst. Reactant feed contains 175 ppm $\mathrm{NO}, 175$ ppm $\mathrm{NO}_{2}, 350$ ppm $\mathrm{NH}_{3}, 14 \% \mathrm{O}_{2}, 2.5 \% \mathrm{H}_{2} \mathrm{O}$ balanced with $\mathrm{N}_{2}$ at a GHSV of 200,000 $\mathrm{h}^{-1}$. (b) NO conversions as a function of temperature calculated using data from (a). (c) Temperature-programmed desorption profiles obtained after reaction.

Figure 12 (a) Solid state ${ }^{27}$ Al-NMR spectra for the fresh and HTA Fe/SSZ-13 samples. The bottom spectra are catalyst mass and scan number normalized for direct comparison. The upper spectrum is a magnified view for the HTA sample in order to provide more details. (b) Solid state ${ }^{27}$ Al-NMR spectra of the fresh and HTA Cu/SSZ-13 samples. The spectra are catalyst mass and scan number normalized. 


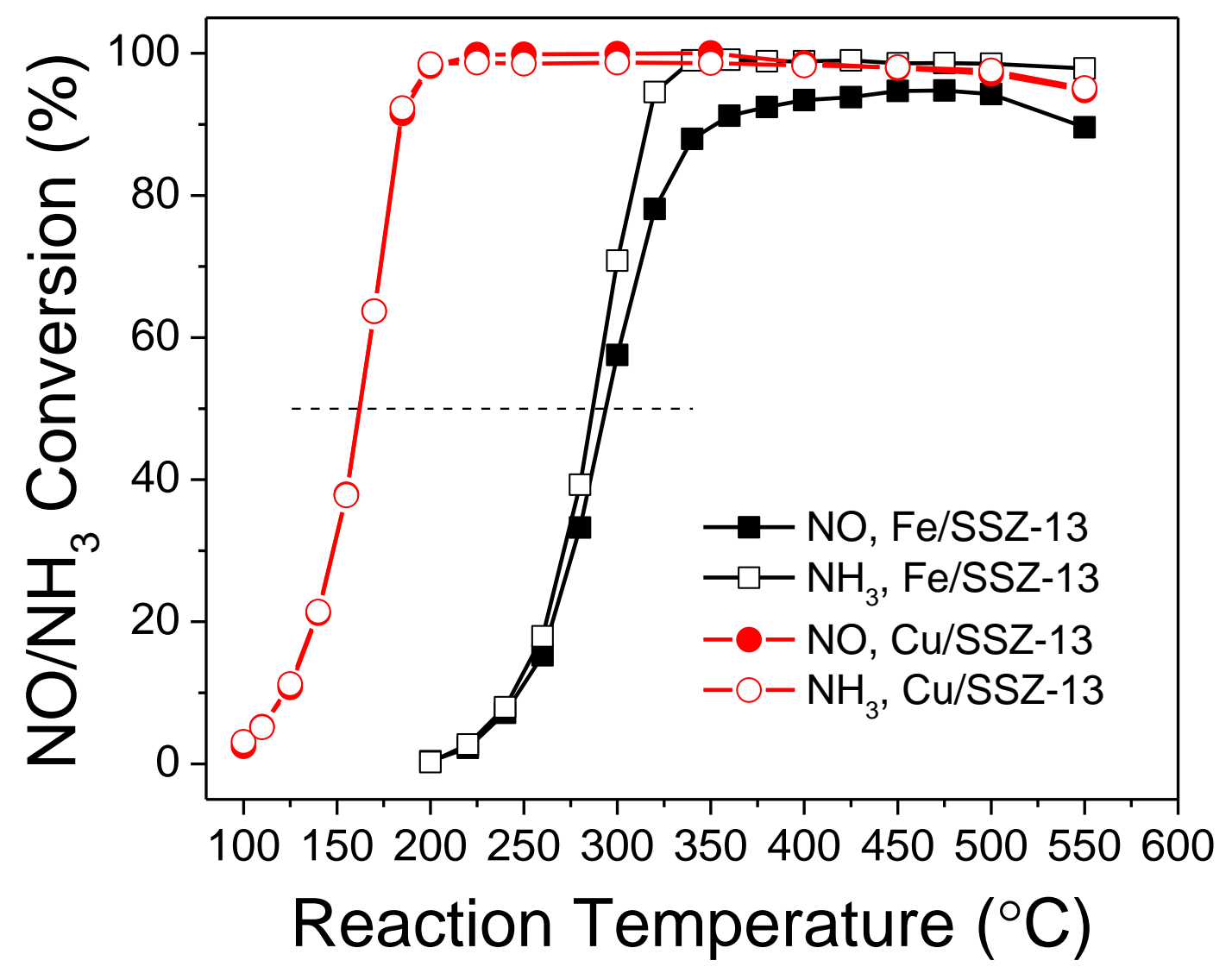

Gao, et. al., Figure 1 
(a)

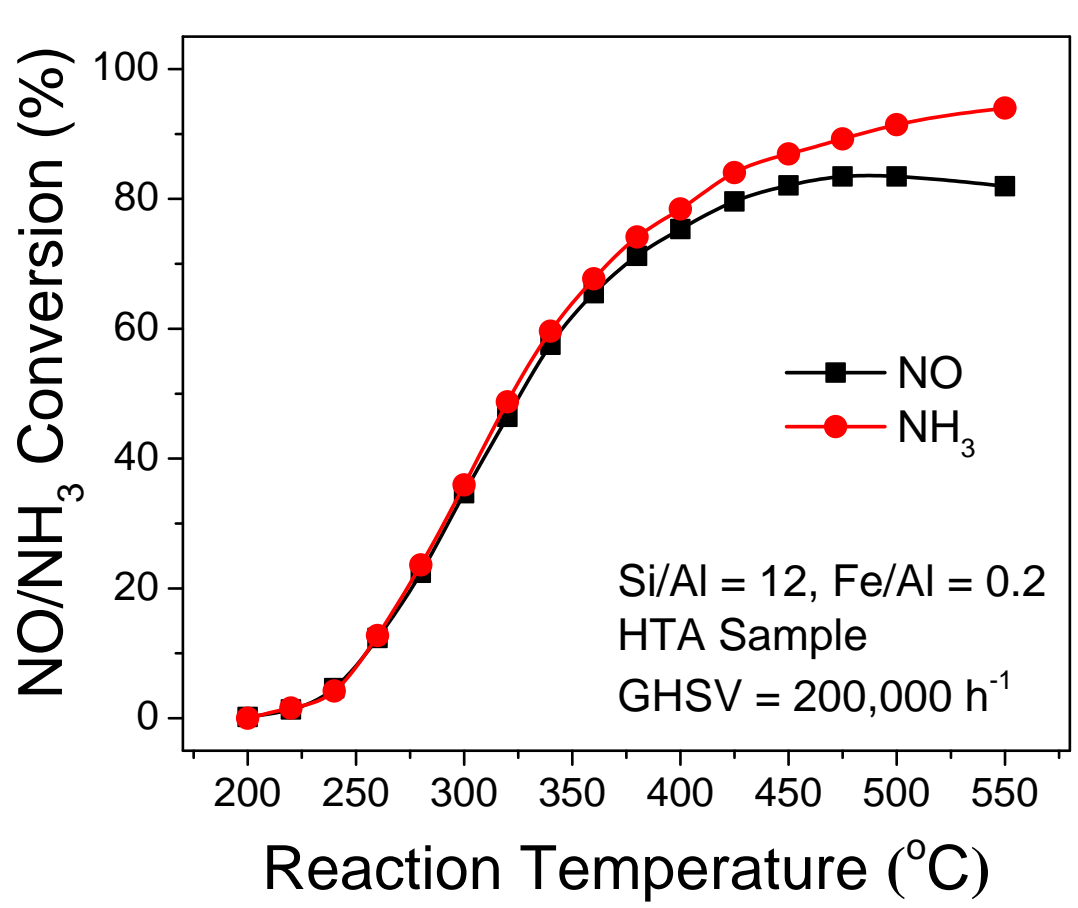

(b)

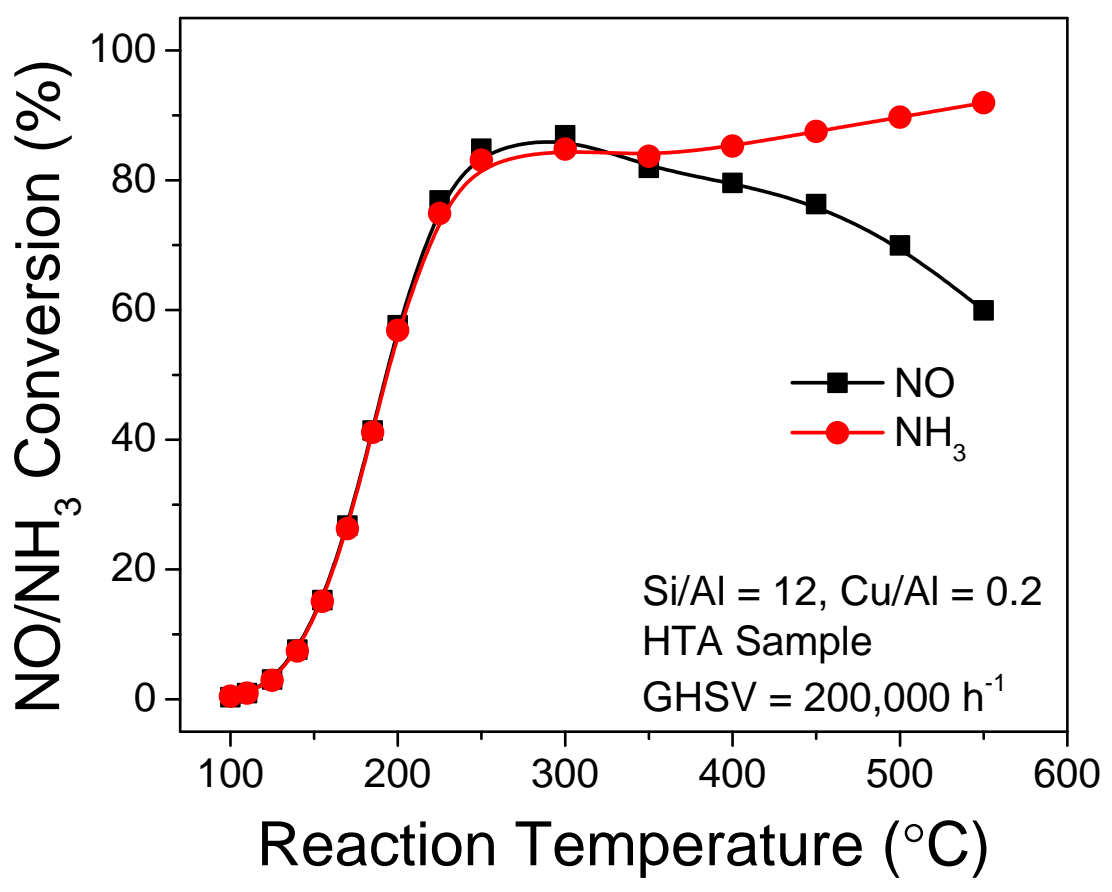

Gao, et. al., Figure 2 
(a)

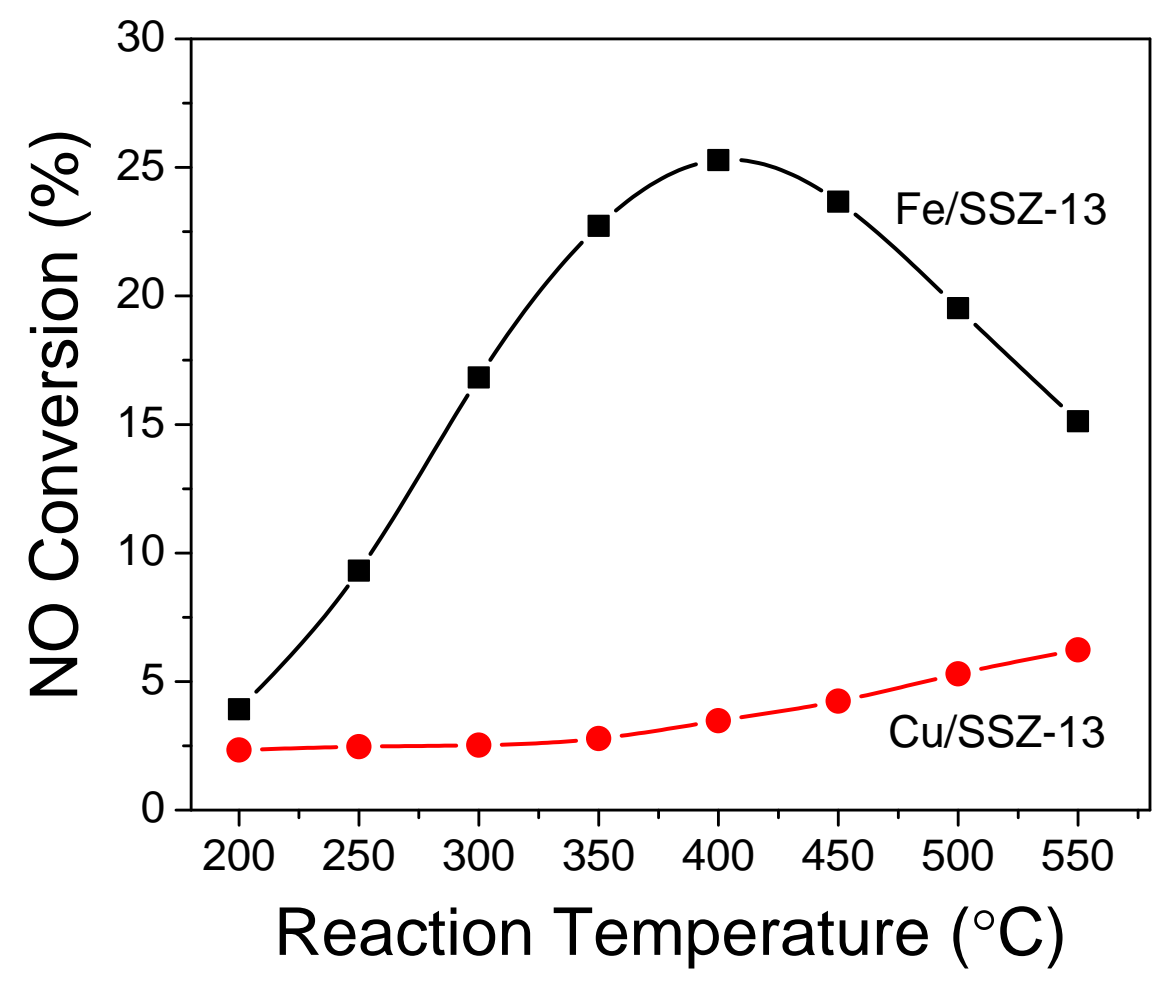

(b)

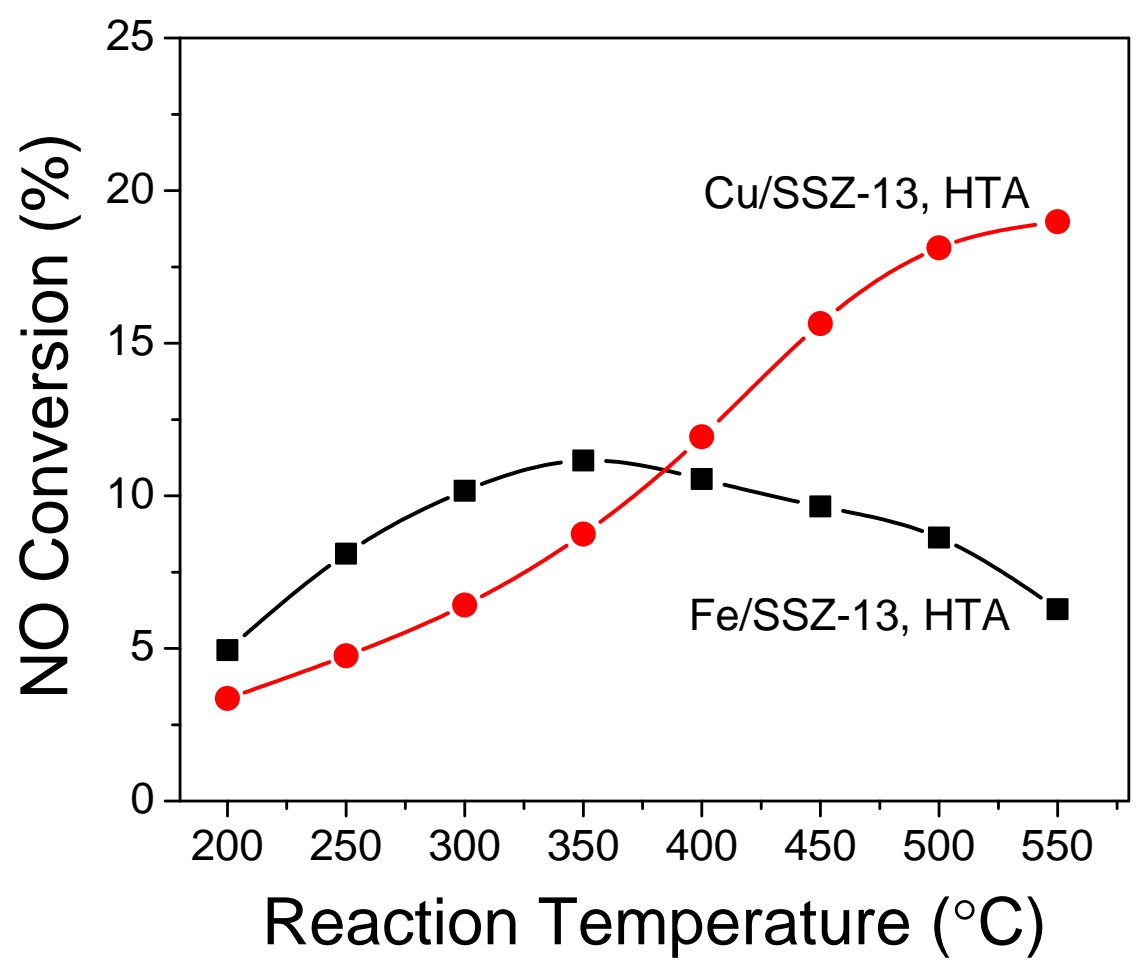

Gao, et. al., Figure 3 
(a)

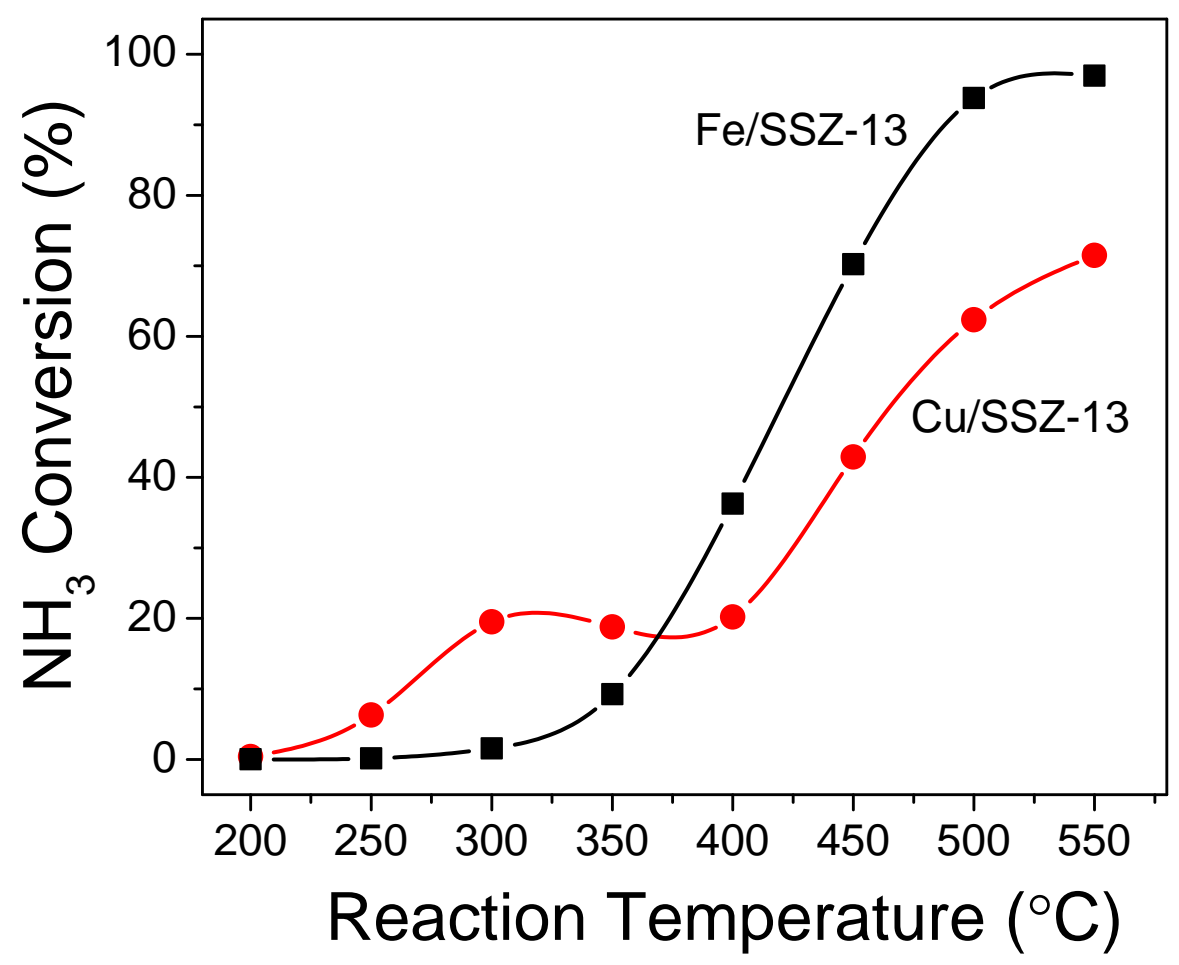

(b)

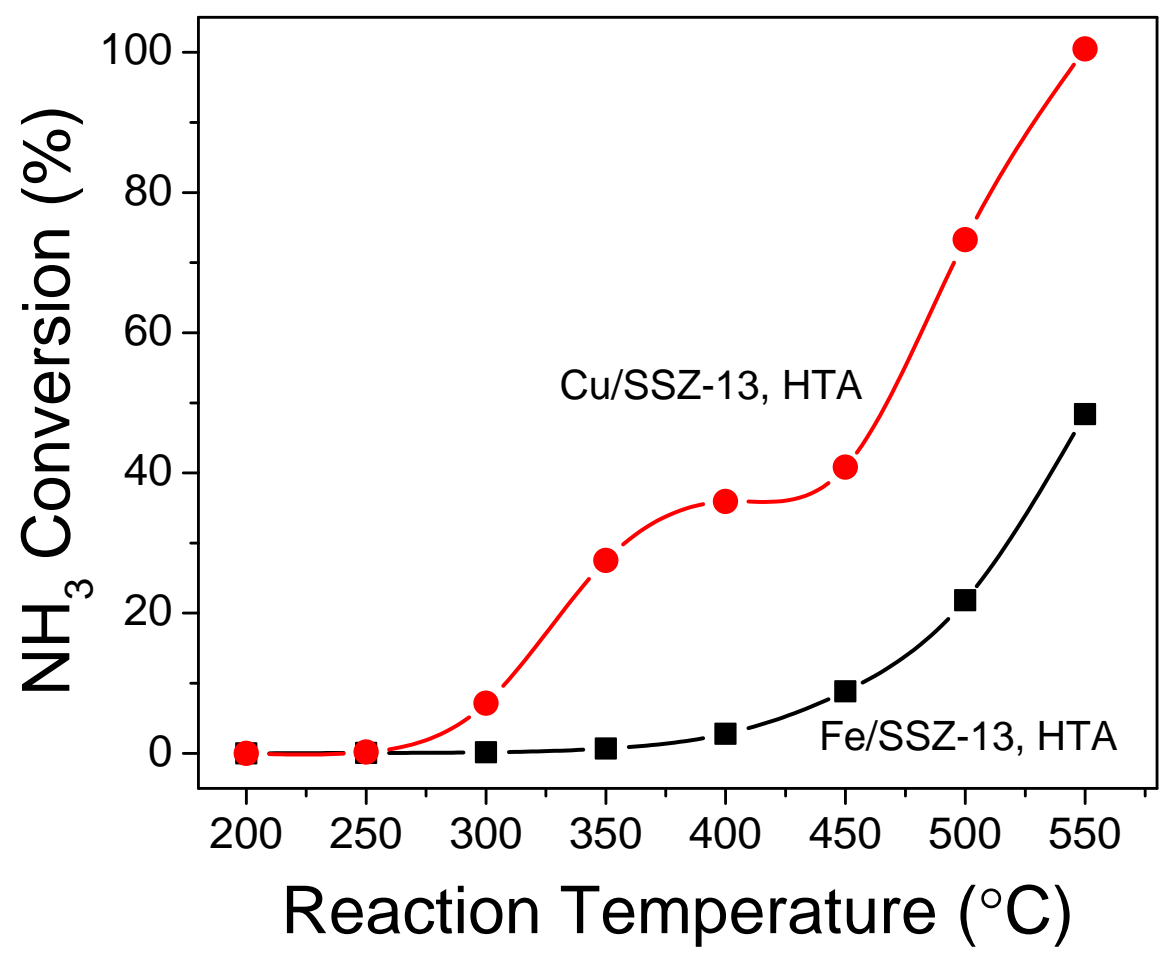

Gao, et. al., Figure 4 
(a)

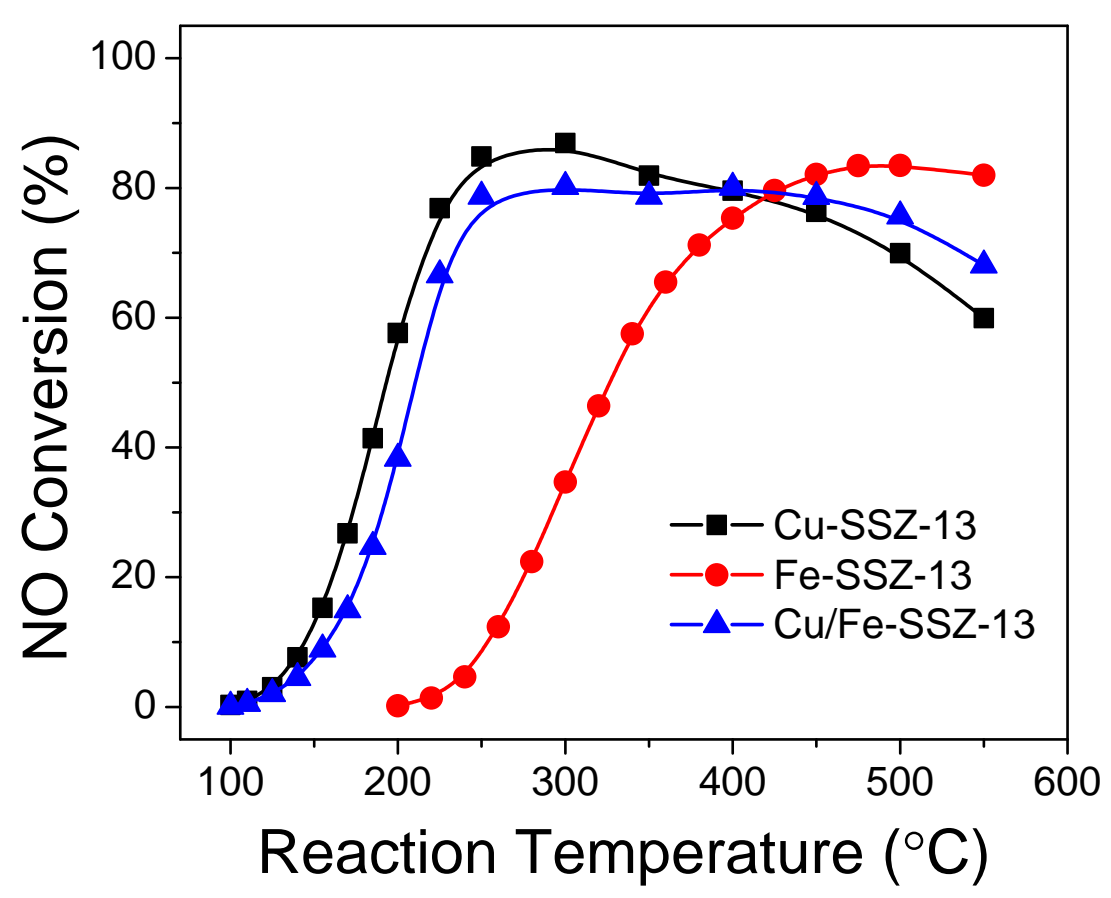

(b)

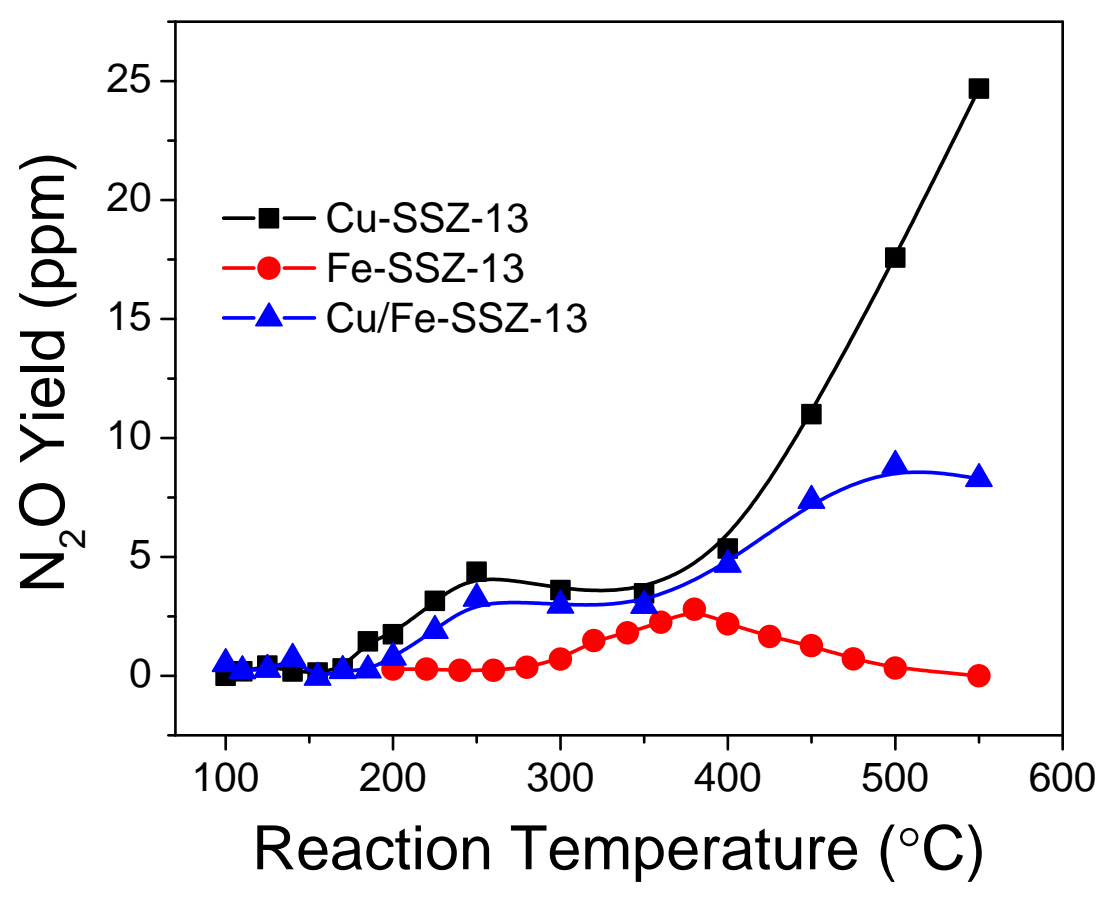

Gao, et. al., Figure 5 
(a)

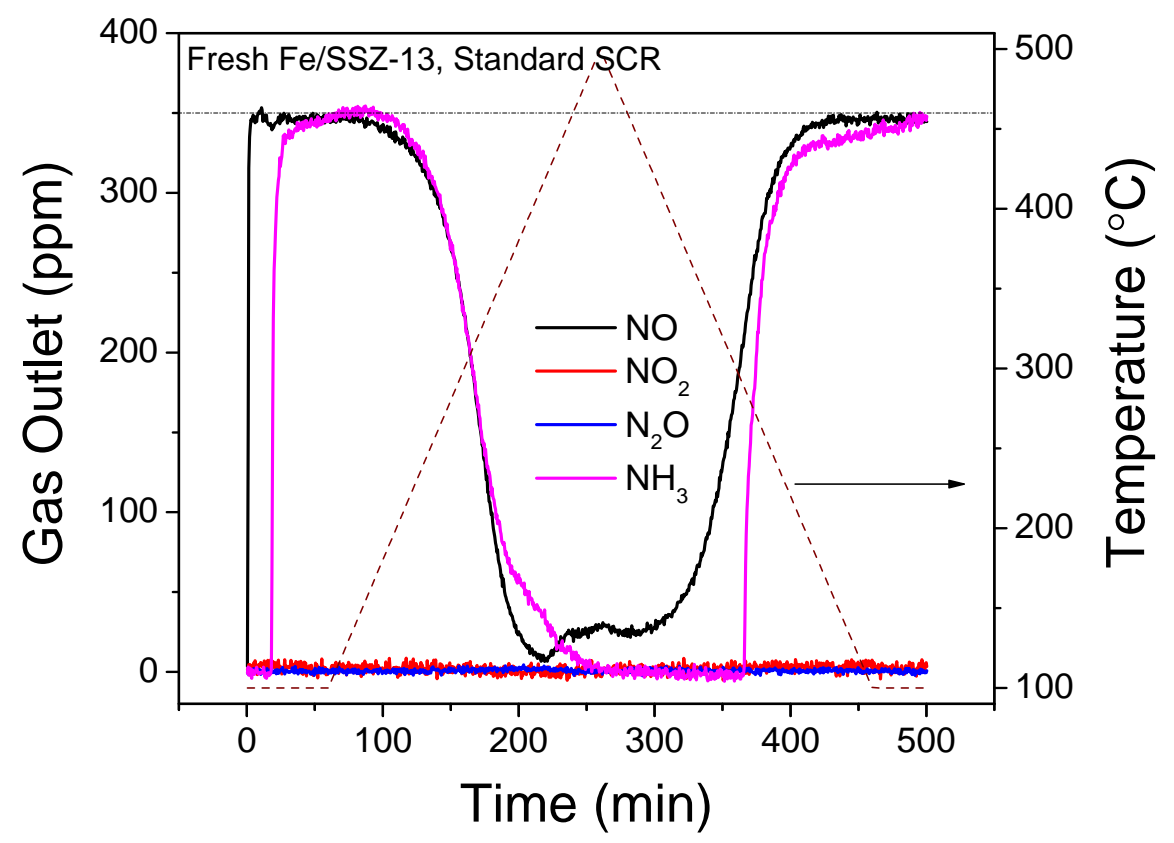

(b)

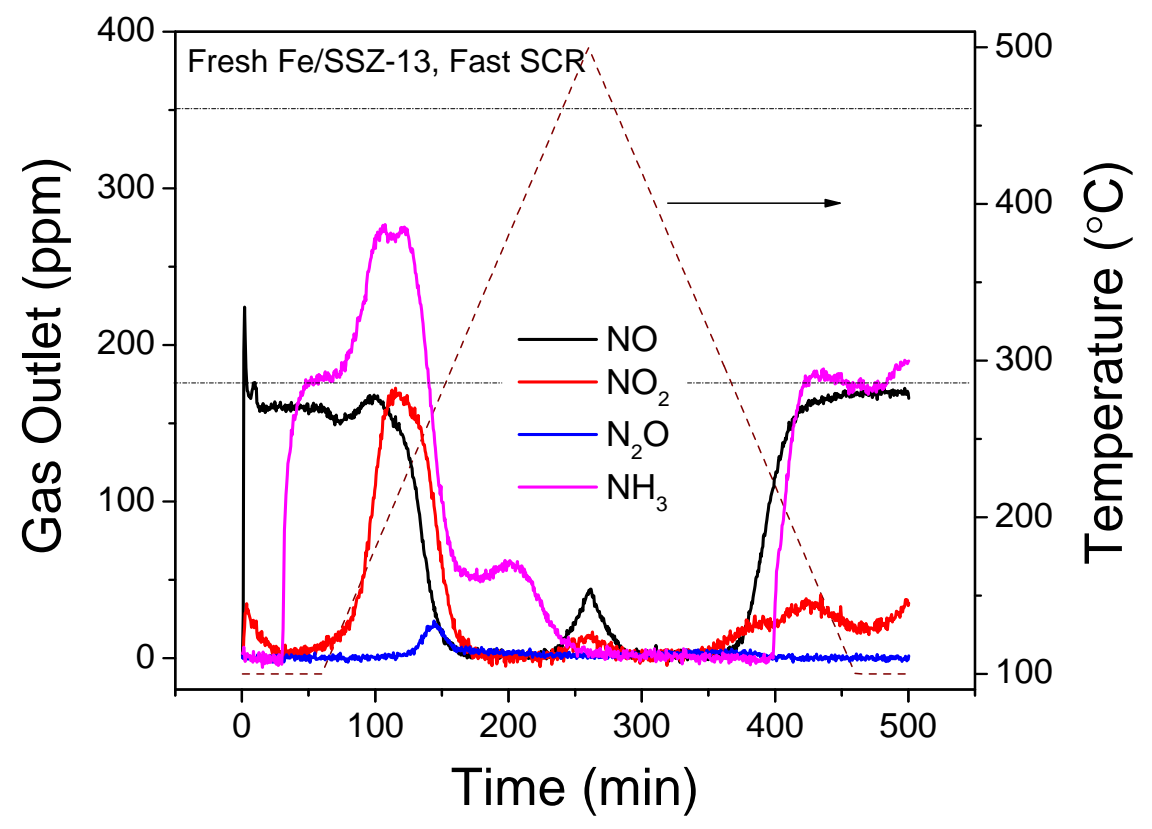

Gao, et. al., Figure 6 
(a)

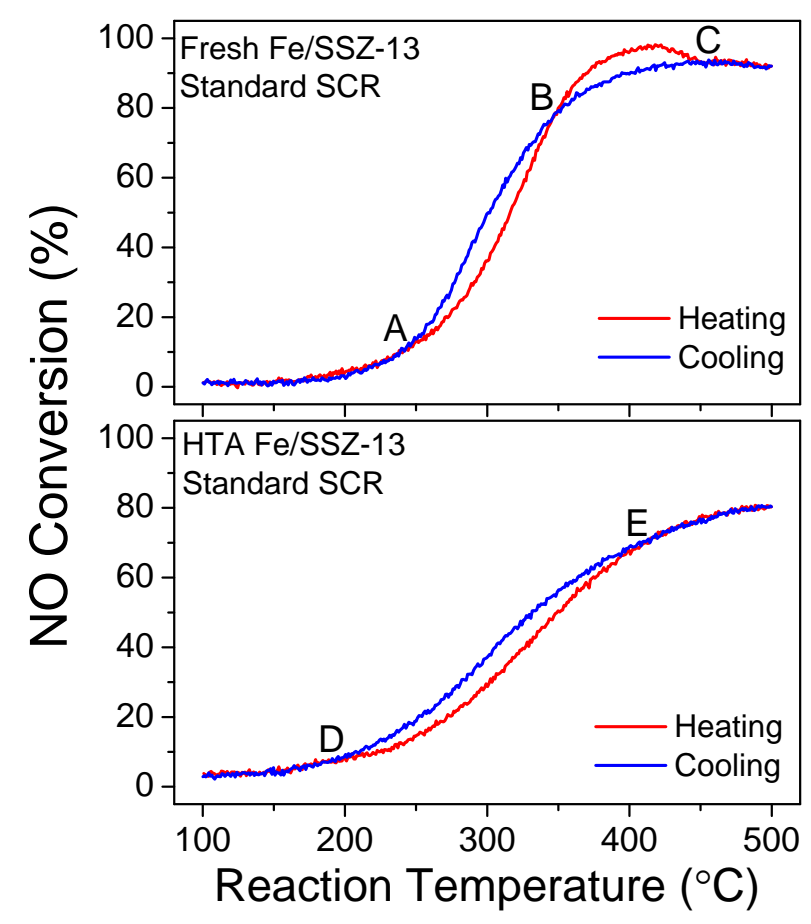

(b)

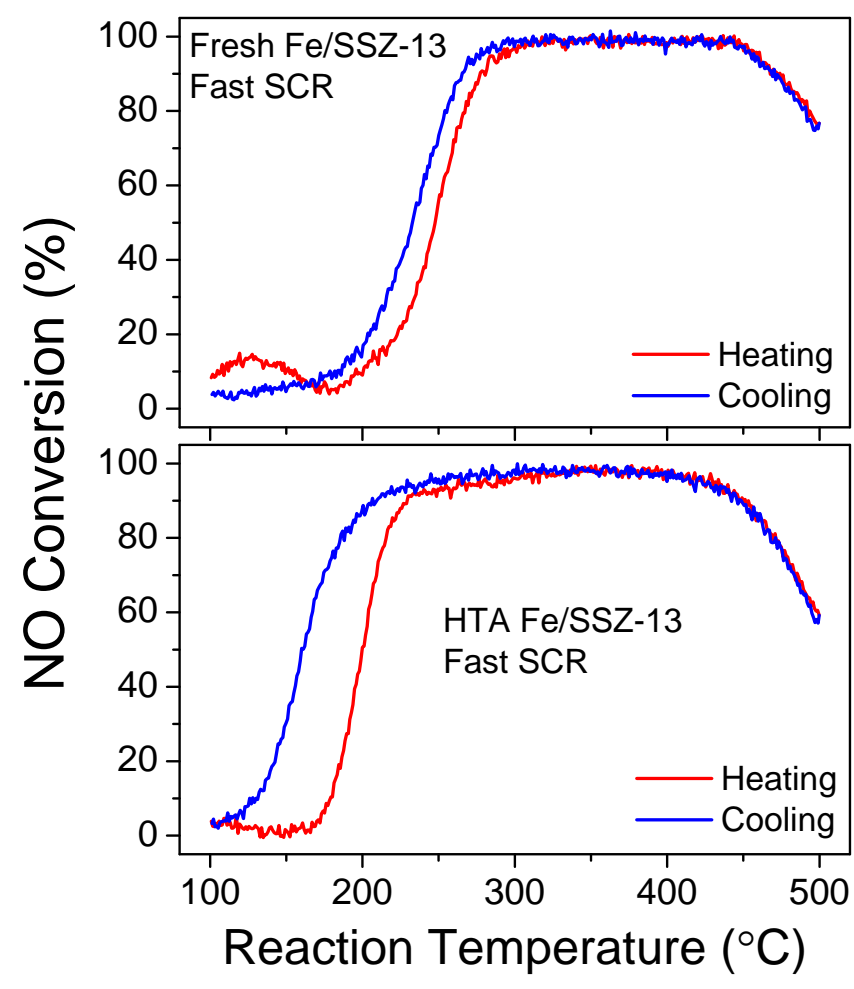

Gao, et. al., Figure 7 
(c)

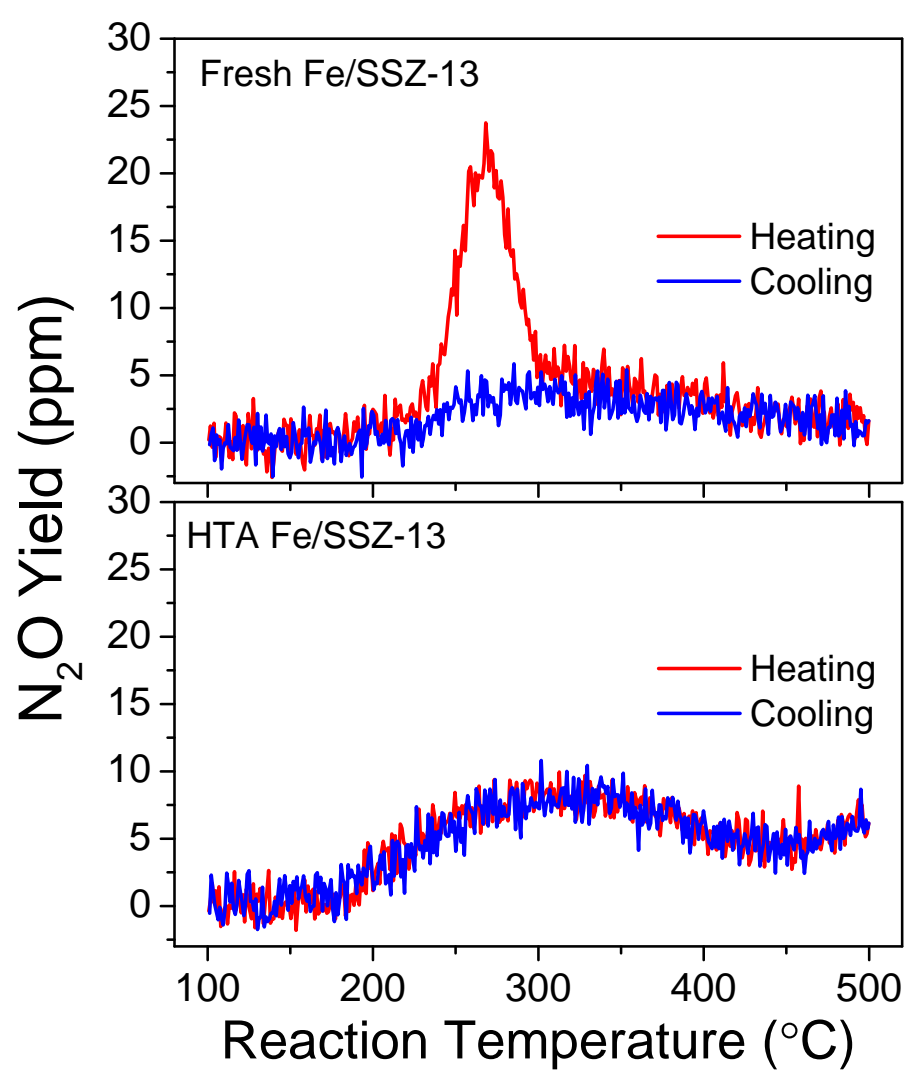

Gao, et. al., Figure 7(cont.) 
(a)

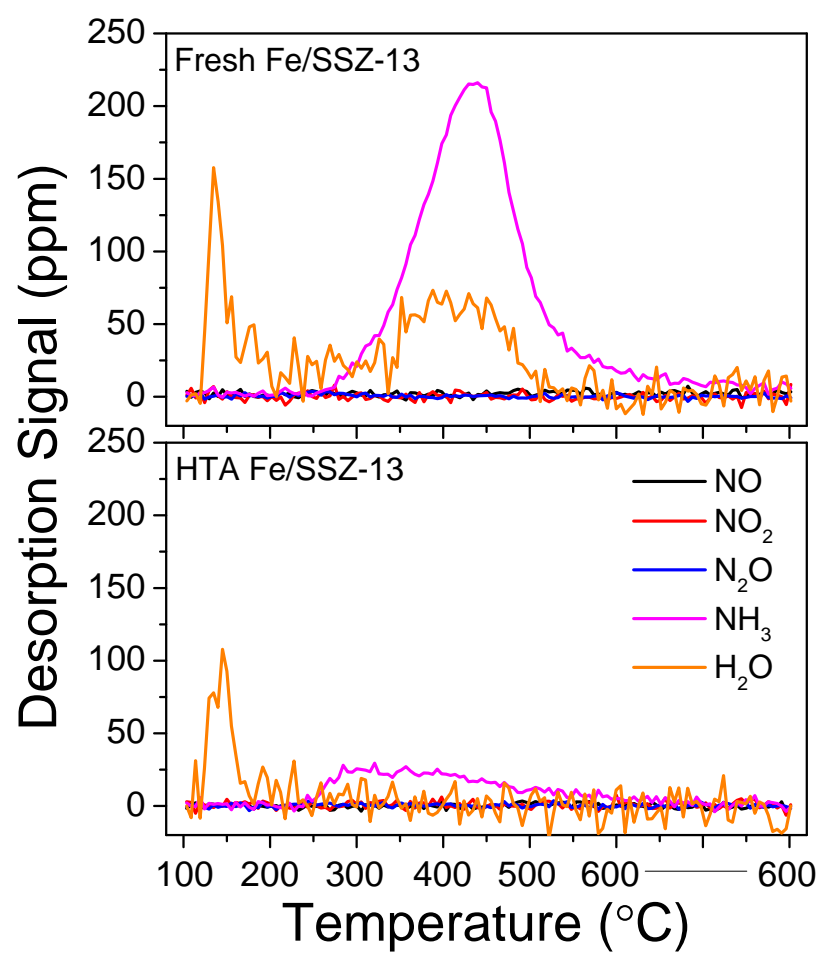

(b)

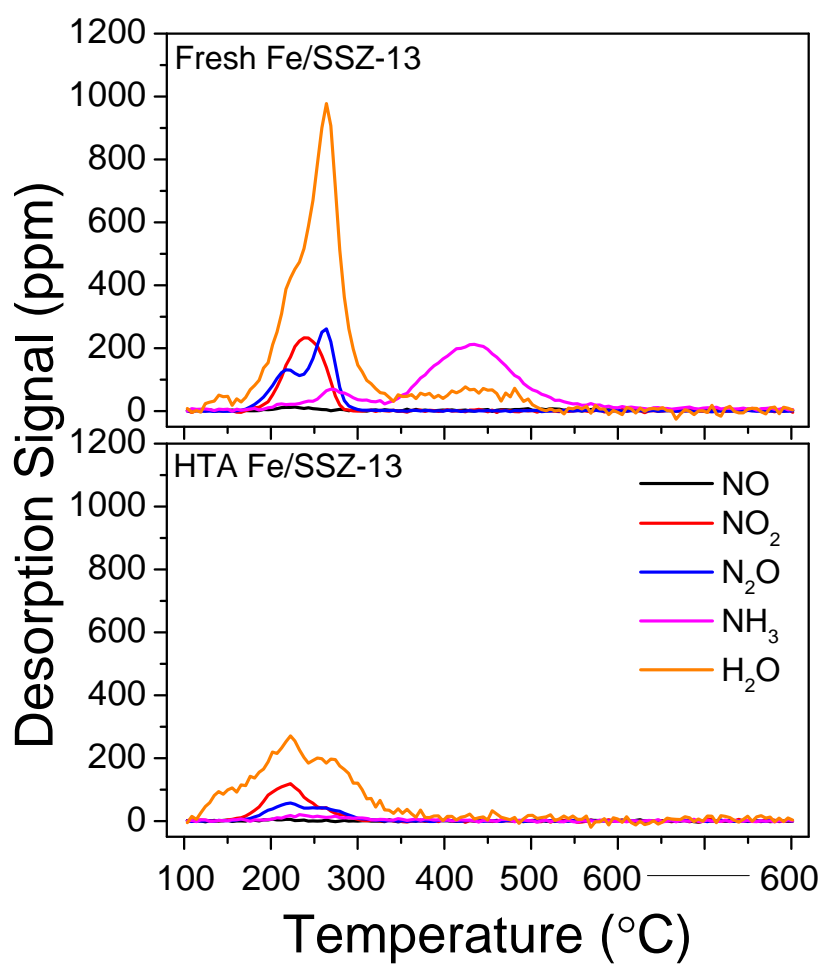

Gao, et. al., Figure 8 
(a)

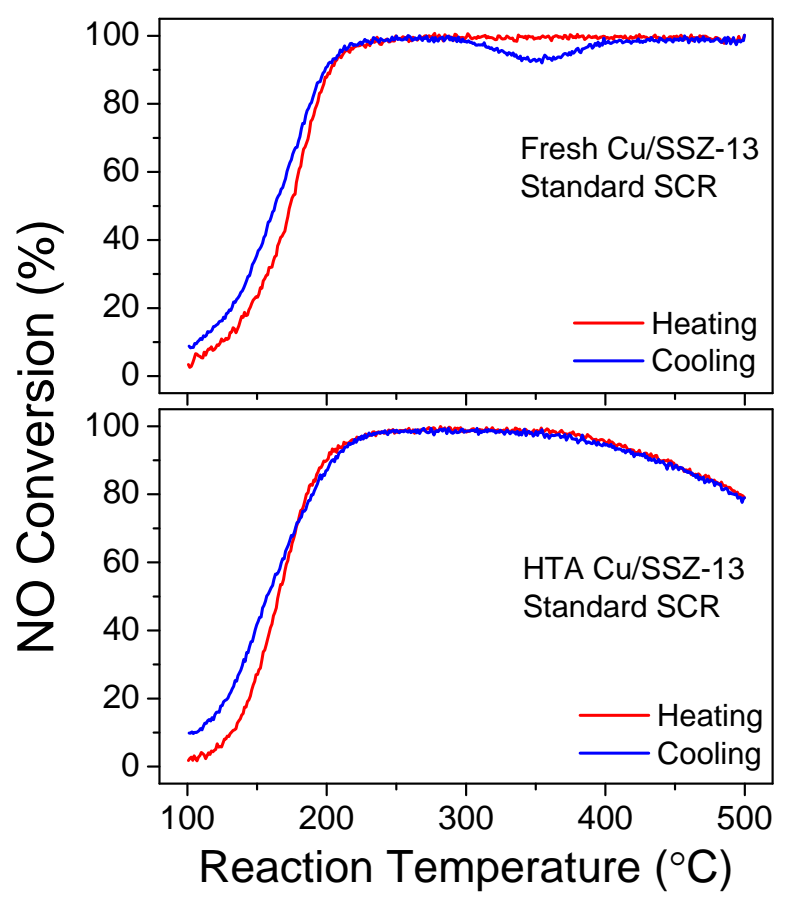

(b)

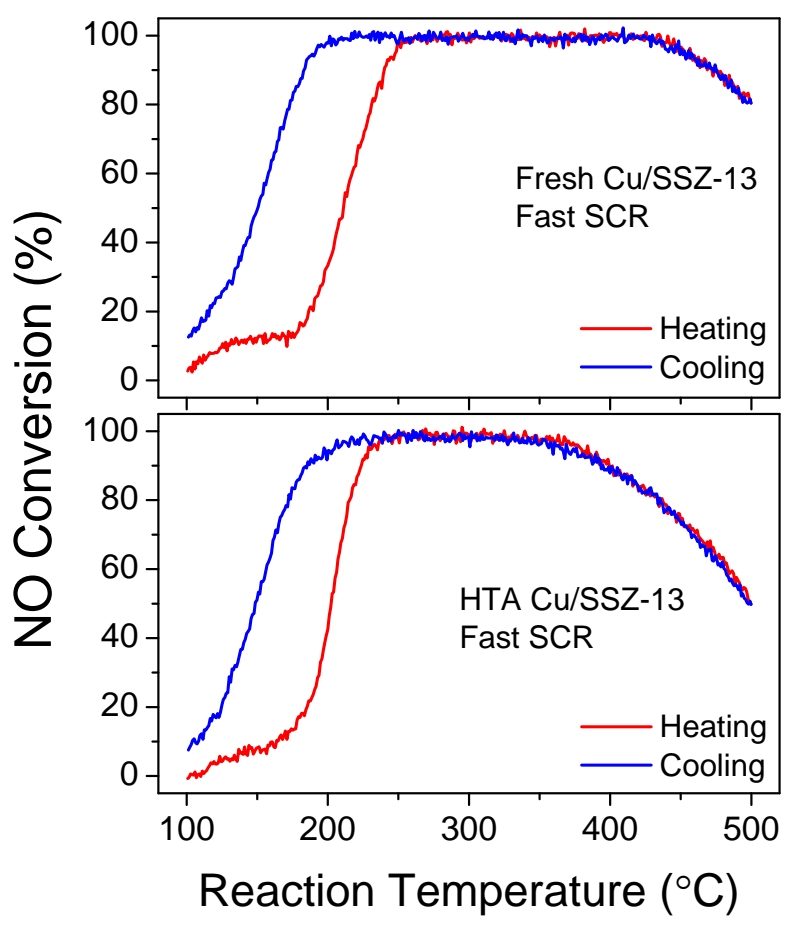

Gao, et. al., Figure 9 
(c)

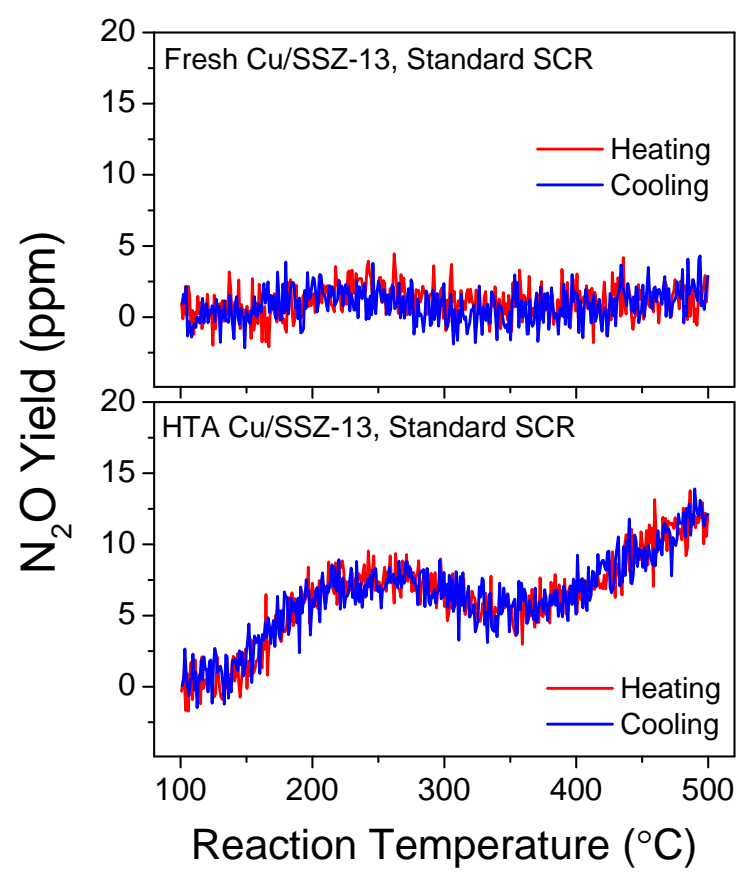

(d)

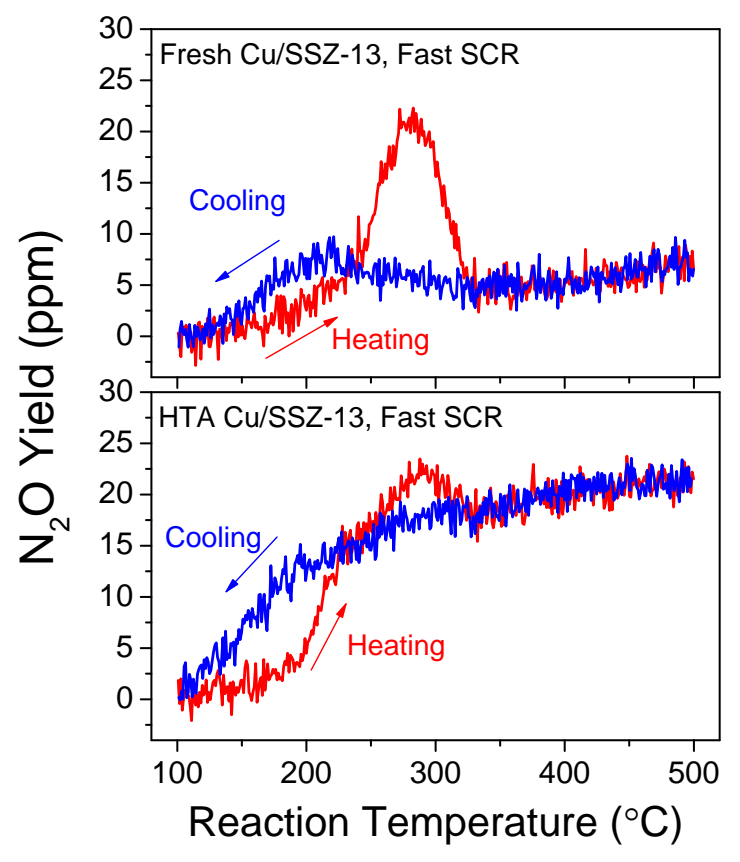

Gao, et. al., Figure 9 (cont.) 
(a)

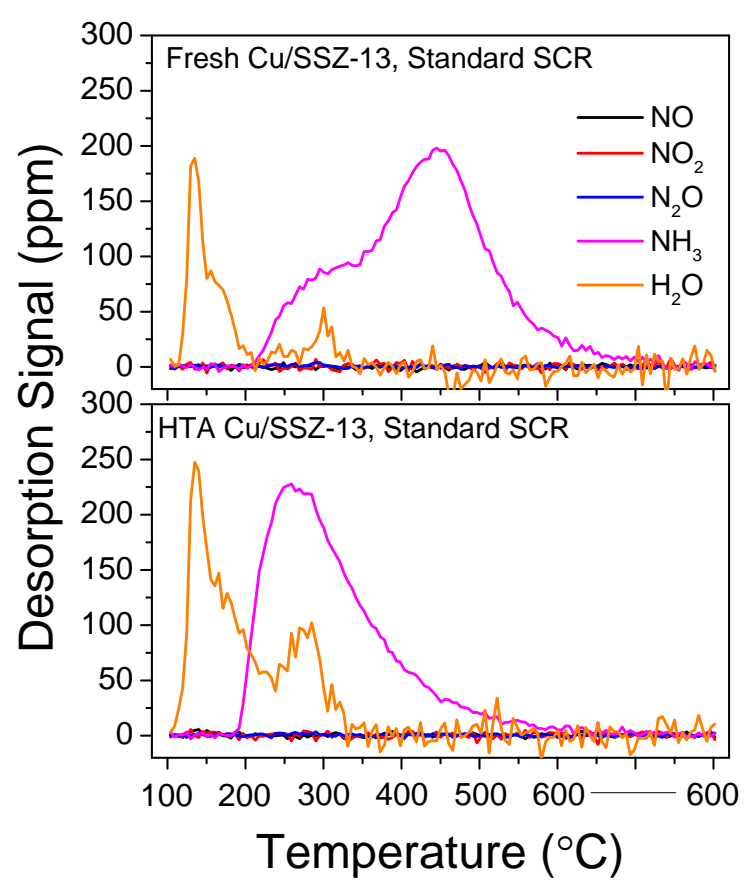

(b)

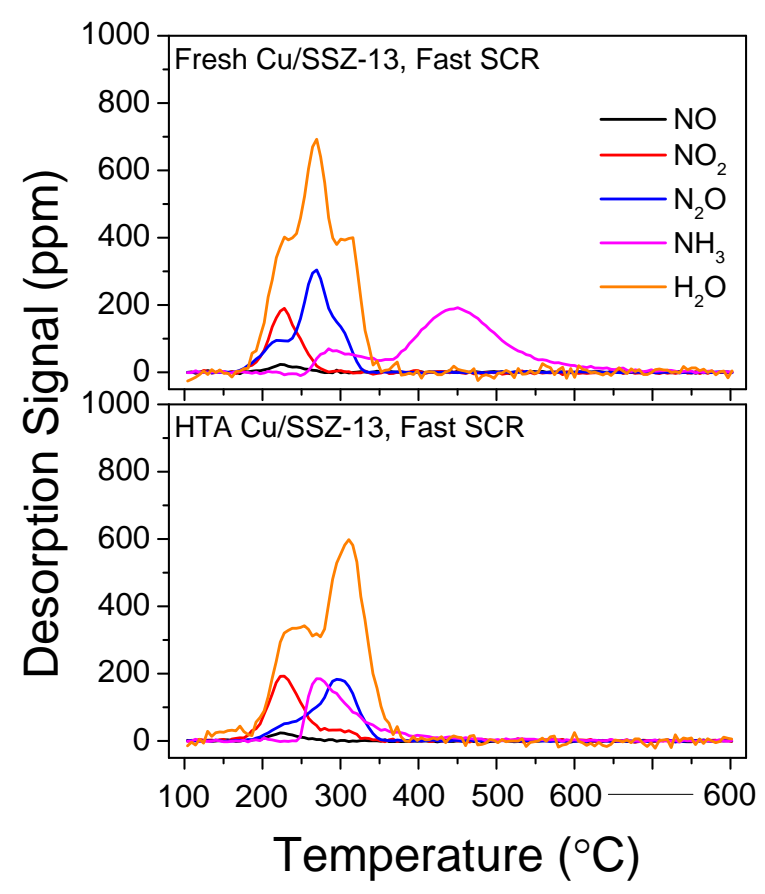

Gao, et. al., Figure 10 
(a)

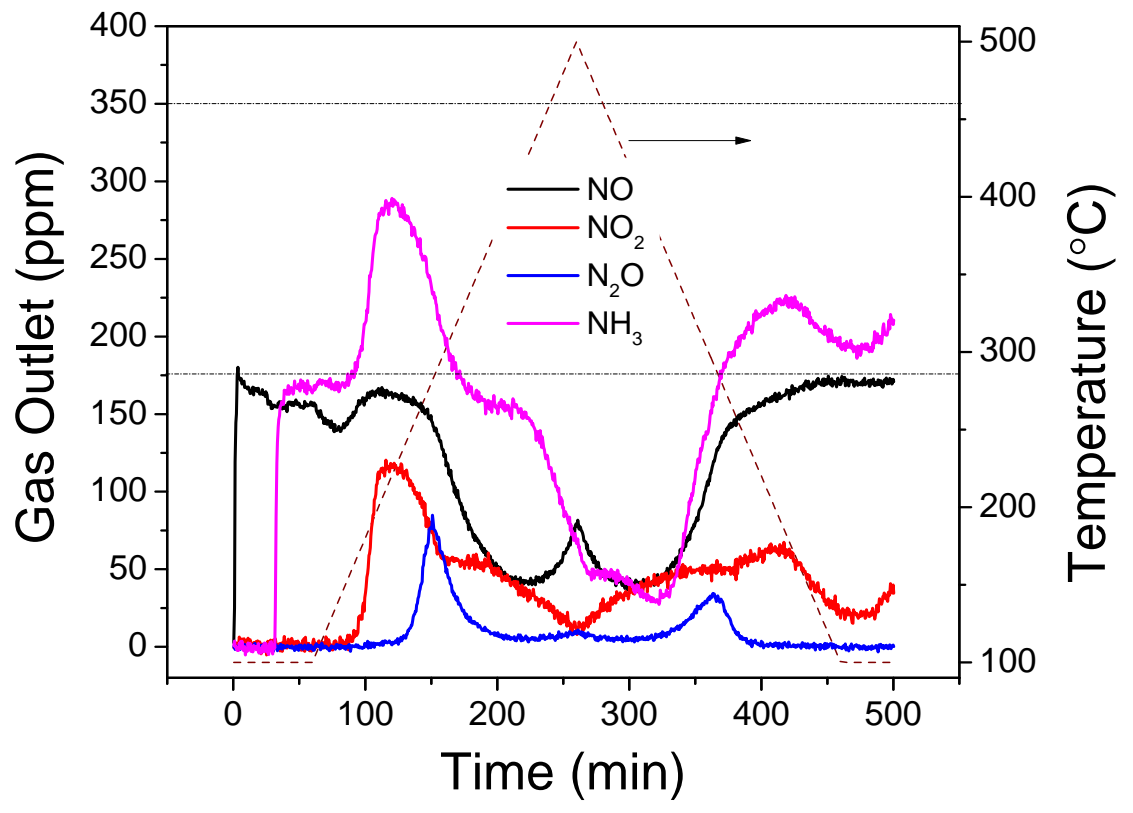

(b)

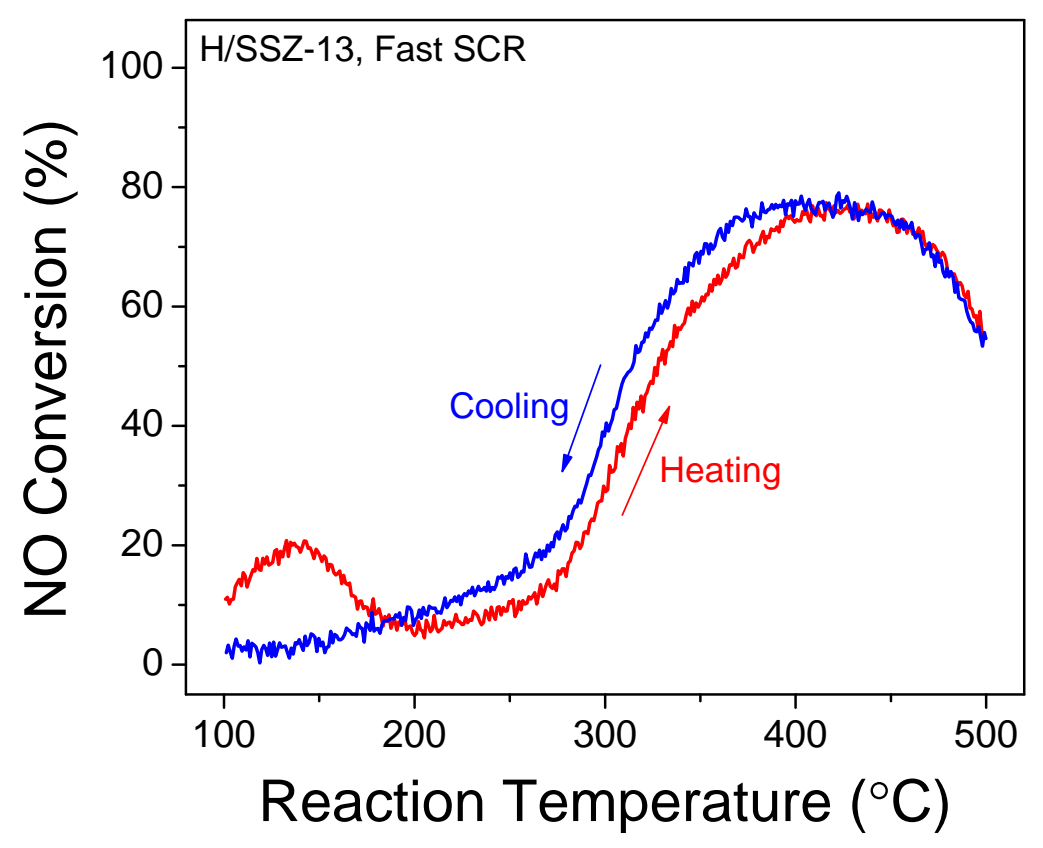

Gao, et. al., Figure 11 
(c)

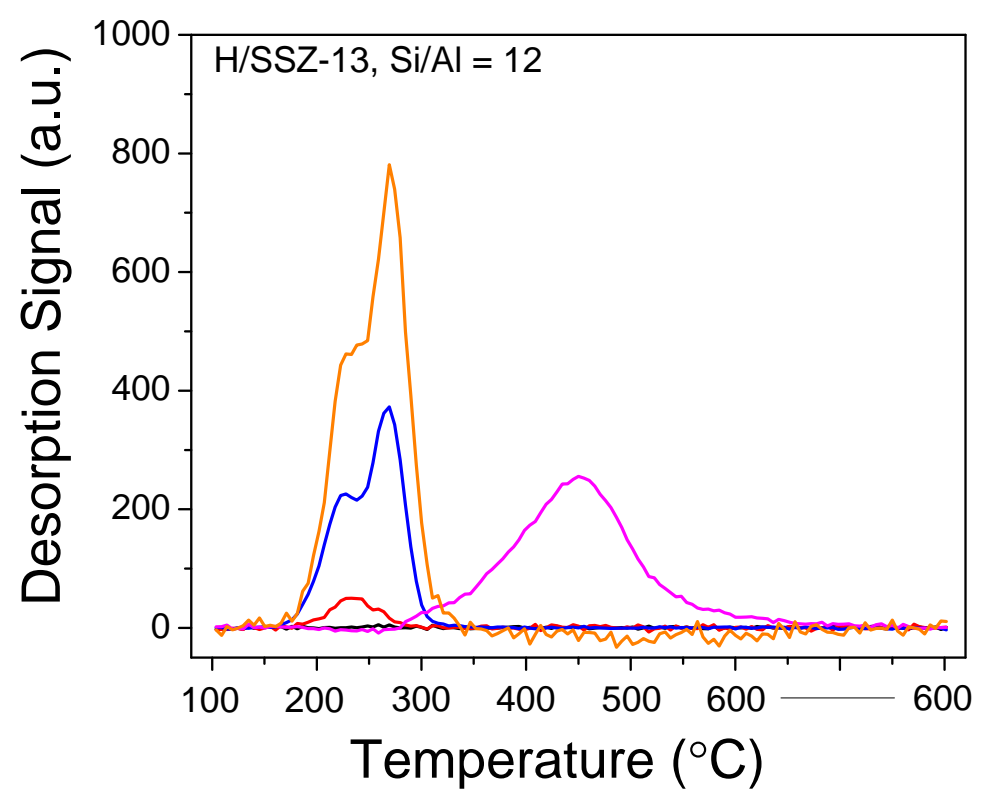

Gao, et. al., Figure 11 (cont.) 
(a) HTA, magnified

Fe/SSZ-13

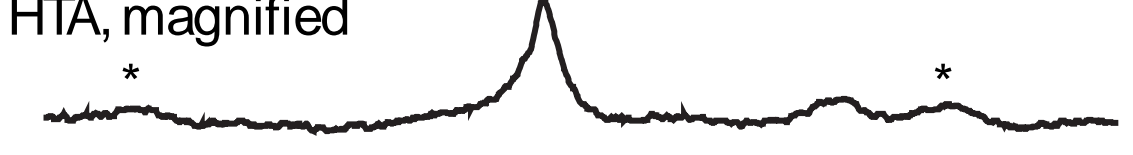

HTA, normalized

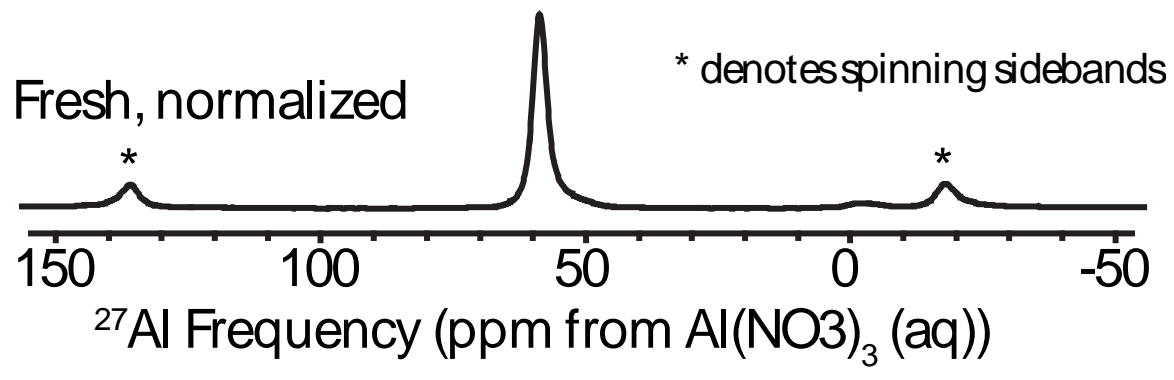

(b)

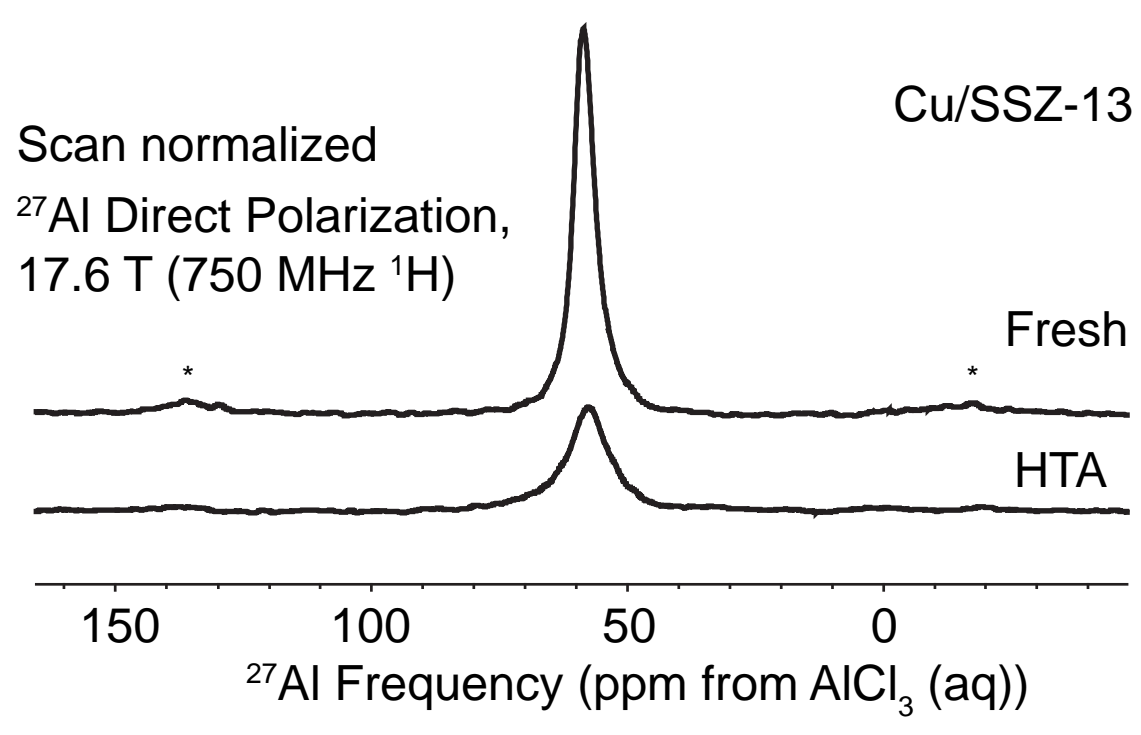

Gao, et. al., Figure 12 


\section{Graphical abstract}
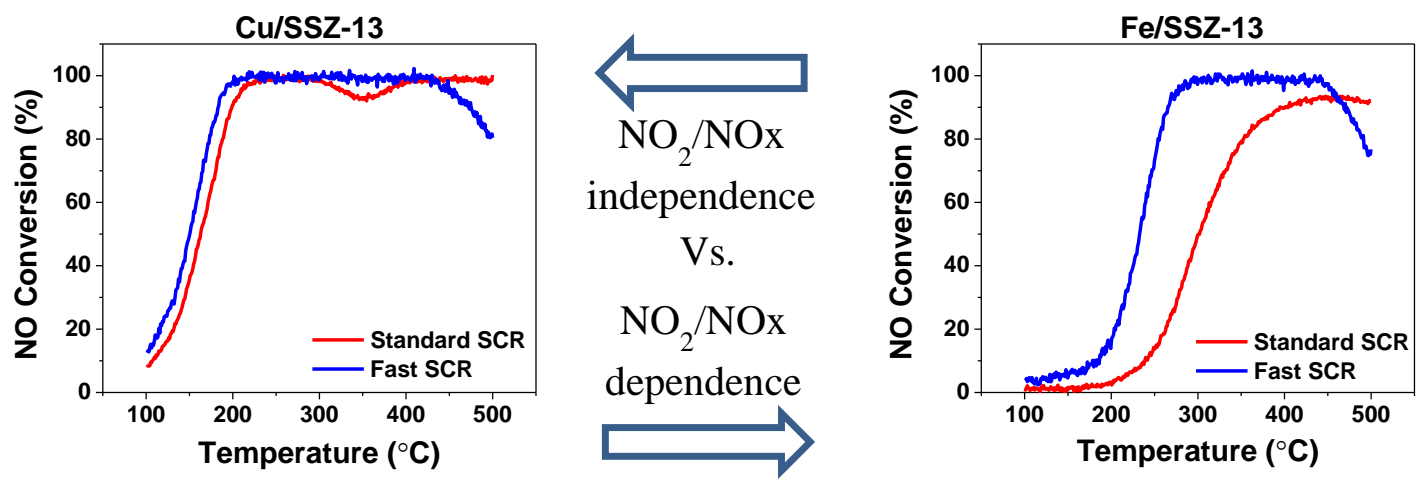